\title{
Pigouvian tax, abatement policies and uncertainty on the environment
}

\author{
Donatella Baiardi · Mario Menegatti
}

Received: 11 August 2010 / Accepted: 15 February 2011 / Published online: 6 March 2011

(C) Springer-Verlag 2011

\begin{abstract}
The paper examines the effects of environmental uncertainty on Pigouvian tax and abatement policy used, either separately or contemporaneously, to counteract pollution. We discuss these effects by introducing three kinds of risk: risk on the environmental quality, risk on the impact of pollution and risk on the impact of abatement. For each case we determine the conditions ensuring that risk increases the size of public intervention and provide an economic interpretation and some parallelisms with other risk problems. The last part of the paper generalizes some of our results to the case of $N$-th order risk changes.
\end{abstract}

Keywords Pigouvian tax · Abatement policies · Environment - Uncertainty · Bivariate utility

JEL Classification $\mathrm{H} 23 \cdot \mathrm{D} 81 \cdot \mathrm{Q} 5$

\section{Introduction}

Nowadays environmental problems are a central issue for many developed and developing countries. Pollution and climate change are important challenges for human health and economic growth. Defining appropriate economic policies for containing

\footnotetext{
D. Baiardi

Dipartimento di Economia Politica e Metodi Quantitativi,

Università di Pavia, Pavia, Italy

M. Menegatti ( $\bowtie)$

Dipartimento di Economia, Università di Parma, Parma, Italy

e-mail: mario.menegatti@unipr.it
} 
environmental degradation and eventually improving environmental quality is now a priority for many governments. ${ }^{1}$

The economic effects of pollution and environment degradation have been widely analyzed in the literature. On one hand, these papers show the relevance of environmental change for different economic issues. In this field, in particular, the effects on economic growth and welfare have been both studied from a theoretical standpoint and quantified by simulations and calibrations. ${ }^{2}$

On the other hand, many papers examine appropriate policies in order to reduce environmental degradation. Two policy instruments are most important. The first is abatement policy, which is an intervention, financed by taxation, which directly improves environmental quality. The second is the so-called "Pigouvian tax", first proposed by Pigou (1924), who argued that negative externality due to pollution can be internalized in a competitive market by introducing a tax equal to the social marginal damage caused by environmental degradation. ${ }^{3}$

Although there is a broad consensus on the idea that pollution has important effects for environmental conditions and human life, we also find a widespread uncertainty on the features and the sizes of these effects. A good example of this is the wellknown issue of global warming. First, although the majority of scientists in the climate research community assert that there has been an increase in temperatures due to human activities, others disagree. ${ }^{4}$ Second, even if we believe that global warming is taking place, there is widespread uncertainty on how temperatures will rise ${ }^{5}$ and how this will impact on human systems. ${ }^{6}$

The aim of this work is to study the effects of uncertainty on the environment with specific reference to its influence on the implementation of policies used to counteract environmental deterioration. For this purpose we introduce three types of risk, i.e.

\footnotetext{
1 A recent important signal of this importance is the attention paid in all developed countries to the United Nation Summits on Climate Change in Copenhagen (December 2009) and Cancun (December 2010).

2 For a survey of these issues see Baumol and Oates (1988), Nordhaus (1994), Nordhaus and Boyer (2000) and Xepapadeas (2005).

3 For an analysis of the design and the effects of these two policies see respectively Gradus and Smulders (1993), Smulders and Gradus (1996), Economides and Philippopoulos (2008) and Gupta and Barman (2009) for abatement policy and Pigou (1924), Baumol and Oates (1988), Mohtadi (1996) and Helfand et al. (2003) for Pigouvian tax. Note that other possible instruments for public intervention in environmental economics, not analysed in this work, are property rights, binding quota restrictions and markets for pollution permits. 4 On this see, for instance, the debate between the Intergovernmental Panel on Climate Change (IPCC) and the Nongovernmental International Panel on Climate Change (NIPCC).

5 As emphasized by the IPCC: 'Models differ considerably in their estimates of the strength of different feedbacks in the climate system, particularly cloud feedbacks, oceanic heat uptake and carbon cycle feedbacks, although progress has been made in these areas. Also, the confidence in projections is higher for some variables (e.g. temperature) than for others (e.g. precipitation), and it is higher for larger spatial scales and longer time averaging periods' (IPCC 2007, p. 73) and 'Projections of climate change and its impacts beyond about 2050 are strongly scenario- and model-dependent, and improved projections would require improved understanding of sources of uncertainty and enhancements in systematic observation networks' (IPCC 2007, p. 73).

6 On this the IPCC Fourth Assessment Report claims that: 'Effects of climate changes on human and some natural systems are difficult to detect due to adaptation and non-climatic drivers' (IPCC 2007, p. 72). On uncertainty on the economic effects of climatic changes see also Heal and Kriström (2002).
} 
risk on the environmental quality level, risk on the effect of pollution and risk on the impact of the abatement policy.

To our knowledge the effects of uncertainty on the environment was studied in the literature only from a standpoint different from that considered in this work. In particular, among the papers examining this issue, Heal (1984) and Keeler et al. (2004) study the effect of uncertainty on the time of a future change in productivity caused by pollution, inserting an uncertain climate threshold in a model of optimal depletion and in a DICE growth model. ${ }^{7}$ Ulph and Ulph (1997) and Pindyck $(2000,2002)$ analyse the optimal timing for the implementation of an abatement policy in a real option framework. Gollier et al. (2000) investigate conditions on utility functions which ensure that scientific progress reducing uncertainty on the distribution of damage related to consumption (in particular pollution damage) induce an earlier prevention effort. Finally, Soretz (2007) examines optimal pollution taxation in an endogenous growth model where productivity is affected by uncertainty on environmental quality on the basis of a relationship evolving as a stochastic Wiener process.

This paper presents three main differences with regard to the previous literature. First, the papers cited above either do not explicitly consider environmental policies, or, as in the majority of the cases, they study the effect of uncertainty on abatement tax. In this work, we analyze the effect of environmental uncertainty on both Pigouvian and abatement tax, considered both as separate instruments and joint instruments.

Second, the papers cited above make specific assumptions about the distribution of the random process describing risk while our paper does not. ${ }^{8}$ We thus obtain general conclusions which do not depend on the specific distribution introduced. In this field, we also introduce a further generalization, extending our results to the case of the so called ' $N$-th order risk change'. 9

Finally, the existing literature studies a one-argument utility framework where utility depends only on consumption. This implies that environmental risk affects agents' preferences through its effect on consumption, because it impacts on productivity. Environmental risk, however, has mainly a direct effect on utility since environmental quality determines a specific dimension of agents utility, different from consumption.

This framework is clearly related to a recent strand of literature analyzing the effect of the background risk. Background risk is in fact a second source of risk, distinct from financial risk, studied in a two-argument utility model, where the second argument of the utility is related to variables such as health status or environmental quality. In this literature, Pratt (1988), Finkelshtain et al. (1999) and Courbage (2001) study the effect of background risk, and thus of environmental risk, on risk aversion. Courbage and Rey (2007) and Menegatti (2009a,b) analyse the effects of background risk on precautionary saving respectively under some specific assumptions on bivariate risk distribution and in the case of small risks. Finally Denuit et al. (2011) generalize the

\footnotetext{
7 A similar model is used to study uncertainty on future preferences about the environment (given the certain level of future environmental quality) in Beltratti et al. (1998), Ayong Le Kama (2001) and Ayong Le Kama and Schubert (2004).

8 The only exception to this is Gollier et al. (2000), who study a framework where the distribution of a generic random variable is revised by consumers according to the Bayes rule.

9 As defined by Ekern (1980) and Eeckhoudt and Schlesinger (2008).
} 
analysis of optimal saving and investment in the presence of two correlated risks, financial and background.

This paper is organized as follow. Section 2 introduces the model. Section 3 analyses the effect of risk on optimal Pigouvian taxation. Section 4 studies the implication of risk in a model with abatement policies. Section 5 examines a model where both Pigouvian tax and abatement policies are used together. Section 6 presents a generalization of our results in the case of stochastic $N$-th degree risk increase. Section 7 concludes.

\section{The model}

In this section we set up a simple model which compares choice made in the private sector with socially optimal choice. Following an approach widely used in the literature (see, for instance, Mohtadi 1996; Xepapadeas 2005), ${ }^{10}$ choice in the private sector is described by the behaviour of a representative consumer, ${ }^{11}$ while the socially optimal choice is described by the choices made by a benevolent social planner. Different policy instruments will be then introduced in next sections.

We assume that consumer preferences are represented by a bivariate utility function $U(c, q)$. The utility function depends on consumption $c$ and on environmental quality level $q$, where $c$ and $q$ are expressed with different unit of measurement. $U(c, q)$ is increasing and concave with regard to each argument and it is three times continuously differentiable with respect to $c$ and $q$ respectively. Letting $U_{c}=\partial U / \partial c, U_{q}=$ $\partial U / \partial q, U_{c c}=\partial^{2} U / \partial c^{2}, U_{c q}=\partial^{2} U / \partial c \partial q$ and so on, these assumptions mean $U_{c}>0, U_{q}>0, U_{c c}<0$ and $U_{q q}<0$. We emphasize that this last assumption implies aversion toward environmental risk. We introduce this hypothesis since we want to compare optimal choice with and without uncertainty for agents who are affected by risk. For completeness we provide some results for the case of risk neutrality in Appendix A.

Consumption $c$ is composed by exogenous income $y$ and by income derived from production activity. Production activity is financed by investment $s$ and generates an output given by $f(s)$. As usual for production functions, we assume that $f(s)$ is increasing and concave with regard to $s$, such that $f^{\prime}()>$.0 and $f^{\prime \prime}()<$.0 . Consumption $c$ is thus given by $c=y-s+f(s) .{ }^{12}$ The value of $q$ depends on the initial environmental quality level $q_{0}$ and on the damage function $g(s)$, which expresses

\footnotetext{
10 The unique difference with reference to these two papers is that they examine a multiperiod framework while we are studying a static model. Other papers with a very similar approach are Smulders and Gradus (1996), Economides and Philippopoulos (2008) and Angelopoulos et al. (2010).

11 The use of a representative consumer implies that we assume all consumers in the private sector to be homogeneous.

12 Note that since the model is static, we have that investment $s$ and production activity related to it are contemporaneous. This means that the agent has only to choose the optimal fraction of exogenous income $y$ to be destined to production activity (which will depend on marginal productivity). For simplicity we call this fraction 'investment' even though the model does not exhibit any kind of capital accumulation. Note that this setting is equivalent to a framework where the production is carried out by a firm which maximizes its profit $f(s)-s$ and that the consumer is the owner of the firm, so that the profit is a part of her income.
} 
the negative influence of pollution through investment in productive activities. Since larger production implies more pollution, we assume that $g^{\prime}($.) $>0$.

As in much literature on pollution and environment (e.g. Michel and Rotillon 1995; Mohtadi 1996; Helfand et al. 2003; Xepapadeas 2005; Angelopoulos et al. 2010), we assume that pollution is an externality, meaning that consumers do not take it into account when they choose the optimal level of $s$. This assumption generates a difference between consumer behaviour and socially optimal choice, and justifies introducing taxation on polluting activity in the next sections. ${ }^{13}$ A partially alternative approach will be discussed at the end of this section.

The consumer maximisation problem, which considers environmental quality level as given and equal to $q_{0}$, is thus the following:

$$
\max _{s} U\left(y-s+f(s), q_{0}\right)
$$

Optimal investment $s^{\star}$ is determined as the solution of the first-order condition, ${ }^{14}$ which, after some computations, is equivalent to

$$
f^{\prime}\left(s^{\star}\right)-1=0
$$

Note that condition (2) simply implies the equality between marginal cost and marginal benefit of investment $s$.

The externality related to pollution is neglected by the consumer, but considered by the planner. This means that, when we consider the planner's problem, we need to take the effect of $s$ on $q$ into account. So the planner's optimal choice is obtained by maximising

$$
\max _{s} U\left(y-s+f(s), q_{0}-g(s)\right) .
$$

The first-order condition is

$$
U_{c}\left(y-\bar{s}+f(\bar{s}), q_{0}-g(\bar{s})\right)\left(f^{\prime}(\bar{s})-1\right)-U_{q}\left(y-\bar{s}+f(\bar{s}), q_{0}-g(\bar{s})\right) g^{\prime}(\bar{s})=0
$$

where $\bar{s}$ is the planner optimal investment level. We assume that the second-order condition ensuring $\frac{\partial^{2} U}{\partial s^{2}}<0$ is satisfied. ${ }^{15}$ This condition implies the equality between social marginal cost and marginal benefit of investment $s$. Note that both cost and

\footnotetext{
${ }^{13}$ In fact, without the externality the consumer would limit emissions in order to avoid an excessive pollution and taxation on polluting activity would be not necessary.

14 It is clear that, given our assumption on $U(c, q)$ and $f(s)$ the second-order condition of the consumer's problem is satisfied.

15 The second-order condition for the planner problem is $U_{c c}\left(y-s+f(s), q_{0}-g(s)\right)\left[f^{\prime}(s)-1\right]^{2}+$ $U_{c}\left(y-s+f(s), q_{0}-g(s)\right) f^{\prime \prime}(s)+U_{q q}\left(y-s+f(s), q_{0}-g(s)\right) g^{\prime}(s)^{2}-U_{q}\left(y-s+f(s), q_{0}-\right.$ $g(s)) g^{\prime \prime}(s)-2 U_{c q}\left(y-s+f(s), q_{0}-g(s)\right)\left[f^{\prime}(s)-1\right] g^{\prime}(s)<0$. Note that, given the previous assumptions on $U(c, q)$ and $f(s)$, the condition is automatically satisfied if $g^{\prime \prime}(s) \geq 0$ and $U_{c q} \geq 0$. This last assumption would mean that consumption and environmental quality level are complements. A similar hypothesis was made, for example, by Mohtadi (1996), who shows that an improvement in environmental quality increases economic growth if $U_{c q} \geq 0$.
} 
benefit in (4) are measured in utils. The same is true for consumer's first-order condition before the simplification determining (2), due to the symmetric effect of cost and benefit on consumer's utility.

The comparison between $s^{\star}$ and $\bar{s}$ clearly shows that the consumer chooses a suboptimally larger investment level $s$ due to pollution externality. ${ }^{16}$ This suboptimal result can be removed by the planner by imposing a Pigouvian tax equal to the marginal pollution damage. Furthermore, environmental quality level can be increased by means of abatement policies. The following sections compare the effects of the Pigouvian taxation and abatement policies under risk.

Before examining these effects, it is important to remember that, as explained above, the framework analyzed in this paper assumes that the consumer cares about environmental quality (we consider a two-argument utility function) but without taking into account the influence of her investment on it (generating an externality). ${ }^{17}$ A partially different approach could assume that the consumer does not care about the environment (she has a one-argument utility) and the planner maximizes a weighted sum of consumer utility and environmental quality. In this case, we have that the consumer's maximization problem becomes

$$
\max _{s} V(y-s+f(s))
$$

and the planner's problem becomes

$$
\max _{s} \alpha V(y-s+f(s))+(1-\alpha) G\left(q_{0}-g(s)\right)
$$

where $\alpha$ and $(1-\alpha)$ are the weights of consumer utility and environmental quality.

In the first of these two problems it is clear that the consumer's first-order condition is exactly equal to (2). ${ }^{18}$ In the planner's problem we get that socially optimal level of investment $\bar{s}$ is given by

$$
\alpha V^{\prime}(y-\bar{s}+f(\bar{s}))\left(f^{\prime}(\bar{s})-1\right)=(1-\alpha) G^{\prime}\left(q_{0}-g(\bar{s})\right) g^{\prime}(\bar{s}) .
$$

It is clear that this condition is a particular case of (4) where $U_{c}(y-\bar{s}+f(\bar{s})$, $\left.q_{0}-g(\bar{s})\right)=\alpha V^{\prime}(y-\bar{s}+f(\bar{s}))$ and $U_{q}\left(y-\bar{s}+f(\bar{s}), q_{0}-g(\bar{s})\right)=(1-\alpha) G^{\prime}\left(q_{0}-g(\bar{s})\right)$. This occurs since the utility function $\alpha V(y-s+f(s))+(1-\alpha) G\left(q_{0}-g(s)\right)$ can be seen as a separable formulation (i.e. a formulation where the cross-derivate $U_{c q}$ is null) of function $U\left(y-s+f(s), q_{0}-g(s)\right)$. Given this equivalence, the results obtained using the framework described by Eqs. (1) and (3) also hold for the alternative framework described by Eqs. (5) and (6).

\footnotetext{
16 The right-hand side of (4) is positive, while the right-hand side of (2) is null. Since $f^{\prime}(s)$ is decreasing in $s$, this clearly implies that $s^{\star} \geq \bar{s}$.

17 As for instance in Michel and Rotillon (1995), Mohtadi (1996), Helfand et al. (2003), Xepapadeas (2005) and Angelopoulos et al. (2010).

18 This is obvious since in both settings the consumer considers only the effect of investment on consumption.
} 


\section{Pigouvian tax and uncertainty}

The excess of investment in the consumer's optimal choice shown in the previous section can be removed by means of a Pigouvian tax, i.e. a tax proportional to investment equal to marginal pollution damage. If we introduce the Pigouvian $\operatorname{tax} T_{p}$, the consumer's problem becomes

$$
\max _{s} U\left(y-s+f(s)-s T_{p}, q_{0}\right)
$$

Consumer's optimal investment $s^{\star \star}$ is thus determined in this case by the first-order condition ${ }^{19,20}$

$$
f^{\prime}\left(s^{\star \star}\right)-1=T_{p} .
$$

This means that Eq. (7) defines the decreasing relationship $\left(f^{\prime}(s)\right.$ is decreasing in $\left.s\right)$ between optimal investment level and Pigouvian taxation. Given this condition, the consumer optimal choice coincides with the socially optimal investment $\left(\bar{s}=s^{\star \star}\right)$ if the planner chooses the optimal level of $\overline{T_{p}}$ such as $f^{\prime}(\bar{s})-1=\overline{T_{p}} \cdot{ }^{21}$ In this context we can introduce two alternative types of environmental risk: 'risk on environmental quality level' ( $q_{0}$ random) or 'risk on the effect of pollution' ( $g(s)$ random). Note that the second case describes risk on the effect of human activities on the environment, while the first considers risk on environment features. For this reason, the case of $q_{0}$ random can represent a situation where we have risk on the present level of environmental deterioration, but also a situation where we have risk on the possible occurrence of natural disasters not related to human activities (like, for instance, earthquakes, tsunamis and volcanic eruptions). ${ }^{22}$

Before studying optimal Pigouvian taxation under different kinds of risk, a general premise concerning consumer behaviour should be stated. Since all risks analyzed involve the environment and since we assume that the consumer takes environmental quality as given in her choice, consumer optimal behavior under environmental risk is

19 Obviously the condition implies equality between the new marginal cost of investment (incorporating the tax) and investment marginal benefit.

${ }^{20}$ Note that we introduce Pigouvian tax as a tax on polluting investment $s$. Alternatively it could be introduced as a tax on output $f(s)$. It is easy to see that, in this case, the first-order condition of consumer's problem (3) would become $\left(1-\widehat{T}_{p}\right) f^{\prime}\left(s^{\star \star}\right)-1=0$ where $\widehat{T}_{p}$ is the level of Pigouvian tax on output. Considering this together with (7) we get $\widehat{T}_{p}=1-\frac{1}{T_{p}+1}$, implying that $\widehat{T}_{p}$ is an increasing function of $T_{p}$. For this reason, the results on the larger or smaller size of $T_{p}$ under risk, derived later on, are also correct for $\widehat{T}_{p}$.

${ }^{21}$ Note that, using (4) and (7), we also have the explicit value of $\overline{T_{p}}$ given by

$$
\overline{T_{p}}=\frac{U_{q}\left(y-\bar{s}+f(\bar{s}), q_{0}-g(\bar{s})\right)}{U_{c}\left(y-\bar{s}+f(\bar{s}), q_{0}-g(\bar{s})\right)} g^{\prime}(\bar{s}) .
$$

22 To formalize this idea assume, for instance, that $\tilde{q}_{0}=q_{0}+\tilde{\epsilon}$ where $\tilde{\epsilon}$ is a random variable describing the possible occurrence of a natural disaster. 
the same as we have in the certainty case. To clarify this point, consider for instance the case where $q_{0}$ is random. In this case, the consumer maximization problem becomes

$$
\max _{s} U\left(y-s+f(s)-s T_{p}, \tilde{q_{0}}\right)
$$

Computing the consumer first-order condition shows that it is equal to (7).

It is important to note that this occurs for all the kinds of environmental risk studied in this paper, so that Eq. (7) describes consumer behavior in all the cases analyzed below.

Unlike consumer behavior, the socially optimal level of taxation is determined by taking the effect on environment into account. This level is thus affected by environmental risk. For this reason, we will study the effect of each kind of environmental risk by examining how these risks affect planner's optimal choice.

\section{(a) Risk on environmental quality}

Firstly we study the case where $q_{0}$ is random. We define it as $\tilde{q}_{0}$ and its expected value as $\mathbb{E}\left(\tilde{q_{0}}\right)=q_{0}$. Let us denote $\tilde{s}$ and $\tilde{T}_{p}$ the investment and tax level under risk, while $\bar{s}$ and $\overline{T_{p}}$ are respectively investment and Pigouvian tax in the certainty case.

Under risk, the planner's maximisation problem becomes

$$
\max _{s} \mathbb{E}\left[U\left(y-s+f(s), \tilde{q_{0}}-g(s)\right)\right]
$$

Computing the planner's first-order condition we get

$$
\begin{aligned}
& \mathbb{E}\left[U_{c}\left(y-\tilde{s}+f(\tilde{s}), \tilde{q}_{0}-g(\tilde{s})\right)\right]\left(f^{\prime}(\tilde{s})-1\right) \\
& \quad-\mathbb{E}\left[U_{q}\left(y-\tilde{s}+f(\tilde{s}), \tilde{q}_{0}-g(\tilde{s})\right)\right] g^{\prime}(\tilde{s})=0 .
\end{aligned}
$$

In this case too, once $\tilde{s}$ is determined by (8), the planner can push the consumer to choose the socially optimal level of investment by considering Eq. (7), describing consumer's optimal behaviour. The planner should thus impose a Pigouvian tax such as $f^{\prime}(\tilde{s})-1=\tilde{T}_{p}$. Considering (4), (7) and (8) together, we have that

Proposition 1 Under risk on environmental quality level, conditions $U_{c q q} \leq(\geq) 0$ and $U_{q q q} \geq(\leq) 0$ are sufficient to have $\tilde{T}_{p} \geq(\leq) \overline{T_{p}}$.

Proof See Appendix B.

Proposition 1 shows that the comparison between the optimal level of Pigouvian tax with and without risk depends on the sign of third-order derivatives of the utility function. This conclusion is not unusual in the analysis of risk effects. The most important result in this field is the well-known condition ensuring precautionary saving in a univariate utility and two-period framework. As first shown by Leland (1968) and clearly explained by Kimball (1990), ${ }^{23}$ positive precautionary saving occurs in this

$\overline{23}$ In this field, see also Sandmo (1970), Drèze and Modigliani (1972) and Menegatti (2001). 
case if the third derivative of the utility function (with regard to its unique argument) is positive.

Moving from a univariate to a bivariate utility framework, however, the role of $U_{q q q}$ and $U_{c q q}$ (called 'cross prudence' by Eeckhoudt et al. 2007) is shown in many works. In a bivariate utility two-period model, in particular, the signs of $U_{q q q}$ and $U_{c q q}$ are shown to determine precautionary saving in different contexts together with $U_{c c c}$ (see Courbage and Rey 2007; Menegatti 2009a,b). Similarly the same derivatives are relevant for the determination of saving in the presence of correlated risks (see Denuit et al. 2011). Finally, similar conditions affect the optimal choice of labor supply in a one period bivariate utility model of choice between consumption and leisure (see Chiu and Eeckhoudt 2010).

An interpretation of conditions $U_{q q q} \geq 0$ and $U_{c q q} \leq 0$ can be obtained starting from that of precautionary saving condition provided by Menegatti (2007). ${ }^{24}$ In fact, following Menegatti (2007), the changes in the size of $-U_{q q}$ can be seen as a measure of the changes in the disutility due to risk on environmental quality. ${ }^{25}$ Condition $U_{q q q} \geq 0$ ensures that this disutility is reduced if we increase environmental quality and thus if we reduce pollution. Condition $U_{c q q} \leq 0$ ensures that this disutility is reduced if we decrease consumption and thus if we reduce investment $(\tilde{s} \leq \bar{s})$ below its optimal value determined by condition (4). In conclusion, both the effects described above are related to prudence. The first is a kind of 'prudence about the environment' (greater risk on the environment implies that a better environmental level is desirable), while the second is a kind of negative cross-prudence (greater risk on the environment implies that less consumption is desirable). These two facts together imply that, under risk, we prefer less investment and less pollution.

\section{(b) Risk on the impact of pollution}

We now turn to risk on the pollution effect. For simplicity, we assume that the damage function $g(s)$ is linear defining $g(s)=k s$. Note that under this assumption, Eq. (4) becomes

$$
U_{c}\left(y-\bar{s}+f(\bar{s}), q_{0}-k \bar{s}\right)\left(f^{\prime}(\bar{s})-1\right)-k U_{q}\left(y-\bar{s}+f(\bar{s}), q_{0}-k \bar{s}\right)=0
$$

Under this assumption we introduce risk on parameter $k$. We denote $\tilde{k}$ as random value of $k$ and its expected value as $\mathbb{E}(\tilde{k})=k$. As before, we denote as $\tilde{s}$ and $\tilde{T}_{p}$ investment and Pigouvian tax under risk. The planner's maximisation problem now becomes

$$
\max _{s} \mathbb{E}\left[U\left(y-s+f(s), q_{0}-\tilde{k} s\right)\right]
$$

\footnotetext{
24 On this see also Eeckhoudt and Schlesinger (2006).

25 Following Menegatti (2007) $\mathbb{E}\left[U\left(y-s+f(s), \tilde{q_{0}}-g(s)\right)\right]$ can be written as $U\left(y-s+f(s), q_{0}-\right.$ $g(s))+\Gamma\left(y-s+f(s), \tilde{q_{0}}-g(s)\right)$, where $\Gamma\left(y-s+f(s), \tilde{q_{0}}-g(s)\right)=\mathbb{E}\left[U\left(y-s+f(s), \tilde{q_{0}}-g(s)\right)\right]-$ $U\left(y-s+f(s), q_{0}-g(s)\right)$. The index $\Gamma(.,$.$) is called utility premium (or generalized risk measure) and it$ is a measure of the disutility caused by uncertainty. Following Stone (1970) and Menegatti (2007) we have that, for small risks, $\Gamma(.,.) \cong-\frac{1}{2} U_{q q}(.,.) \sigma^{2}$.
} 
implying a first order condition given by

$$
\mathbb{E}\left[U_{c}\left(y-\tilde{s}+f(\tilde{s}), q_{0}-\tilde{k} \tilde{s}\right)\right]\left(f^{\prime}(\tilde{s})-1\right)-\mathbb{E}\left[\tilde{k} U_{q}\left(y-\tilde{s}+f(\tilde{s}), q_{0}-\tilde{k} \tilde{s}\right)\right]=0
$$

As in the previous case, condition (9) and (10) determine the socially optimal levels of investment respectively without risk $(\bar{s})$ and under risk $(\tilde{s})$. Given these optimal levels, $\overline{T_{p}}$ and $\tilde{T}_{p}$ are determined by Eq. (7). By comparing (9) and (10) and using (7), we get

Proposition 2 Under risk on the effect of pollution, conditions $U_{c q q} \leq(\geq) 0$ and $-k s \frac{U_{q q q}}{U_{q q}} \geq(\leq)-2$ are sufficient to have $\tilde{T}_{p} \geq(\leq) \overline{T_{p}}$.

Proof See Appendix B.

In the case of risk on the pollution effect, we have a higher Pigouvian tax if $U_{c q q} \leq 0$ and $-k s \frac{U_{q q q}}{U_{q q}} \geq-2$. The first condition is the same as obtained in the case of risk on environmental quality, and its interpretation is the same too. The second condition is different from the previous case. In order to explain it, it must first be emphasised that the index $-k s \frac{U_{q q q}}{U_{q q}}$ is a relative prudence index. ${ }^{26}$ The level of relative prudence has been proved to be relevant in cases where a return is uncertain. In particular, Rothschild and Stiglitz (1971) showed that risk on the interest rate (the return of saving) increases saving if the index of relative prudence is larger than 2. Similarly Chiu and Eeckhoudt (2010) showed that the same conditions in Proposition 2 ensure that risk on wages raises the labor supply. ${ }^{27}$ These two results together indicate that a condition of relative prudence is related to risk on returns (either the returns from saving or the return from labor).

The interpretation of condition $-k s \frac{U_{q q q}}{U_{q q}}$ in Proposition 2 is consistent with these conclusions. Indeed, in our framework, parameter $k$ measures the effect of a unit of investment on pollution, and it is thus a kind of 'negative return' of investment in terms of pollution. For this reason, as in the problems cited above, the effect of risk on it depends on the index of absolute prudence. Furthermore, the difference in our condition compared to that in Rothschild and Stiglitz (1971) (a threshold level of -2 instead of 2) occurs since the effect is here a negative return instead of a positive return (we like interest and we dislike pollution). ${ }^{28}$

\footnotetext{
26 Following Pratt (1964) and Kimball (1990) for an univariate utility function $U(x)$ we can define the following indexes: absolute risk aversion $-U_{x x}(x) / U_{x}(x)$, relative risk aversion $-x U_{x x}(x) / U_{x}(x)$, absolute prudence $-U_{x x x}(x) / U_{x x}(x)$ and relative prudence $-x U_{x x x}(x) / U_{x x}(x)$.

27 Chiu and Eeckhoudt (2010) showed that these conditions are sufficient for an increase in labor supply, in case of a mean-preserving spread in wages. The comparison between a known level of wage and a random one can be seen as a specific case of mean-preserving spread.

28 On this last conclusion see also the results in next section.
} 


\section{Abatement policies and uncertainty}

In the previous section we introduced a Pigouvian tax in order to reduce pollution. We now turn to a different policy to improve environmental quality: abatement policy. Abatement (or cleanup) activities can in general be seen as a policy, financed by a lump sum tax $\left(T_{a}\right)$, aimed at reducing environmental degradation due to pollution and increasing environmental quality. ${ }^{29}$

It is important to note that this instrument is completely different from the previous one since it does not affect the level of investment $s$ and the level of emissions due to it. ${ }^{30}$ The policy introduced here is simply a policy which improves environmental quality, and its optimal implementation does not influence the agent's decision problem. ${ }^{31}$ For this reason, the terms $f\left(s^{\star}\right)-s^{\star}$ and $g\left(s^{\star}\right)$ in the maximization problem could be removed in this context. Furthermore implementation of the abatement policy is not specifically linked to the presence of an externality related to pollution. In fact, an optimal abatement policy could also be introduced into a framework where consumers take pollution into account (i.e. in the absence of externalities), if the planner can intervene in order to improve environmental quality.

Nevertheless, in order for the paper to have a unified framework, we retain the terms $f\left(s^{\star}\right)-s^{\star}$ and $g\left(s^{\star}\right)$ in our specification. We emphasize, however, that the problems in Sect. 3 and in Sect. 4 are different and distinct. The two instruments (and the two problems) will be considered together in Sect. 5 .

We assume that the effect of the abatement policy is described by a linear function so that for each tax unit paid we have an increase of $m$ in environmental quality. ${ }^{32}$ Given consumer choice, the planner defines the optimal abatement tax level by solving

\footnotetext{
29 The United Nations defines pollution abatement as technology applied or measure taken to reduce pollution and/or its impacts on the environment (see United Nations 1997). A more accurate terminology would distinguish between 'abatement' and 'mitigation' in pollution and climate change issues respectively. Since our analysis focuses on the role of risk on the environment, this paper aims to study a generic framework which can, in principle, be applied to different environmental problems. For this reason, we use here the word 'abatement' which should be interpreted with a wide meaning.

30 Given the abatement tax $T_{a}$, the consumer's maximization problem is a simple modification of the problem in Sect. 2, given by
}

$$
\max _{s} U\left(y-s+f(s)-T_{a}, q_{0}\right)
$$

Computing the first-order condition, it is easy to see that the optimal investment $s^{\star}$ is still determined by Eq. (2) and does not depend on $T_{a}$. The reason of this result is that the optimal level of investment is determined only by the equality between its marginal cost $(-1)$ and its marginal benefit $\left(f^{\prime}(s)\right)$. If this equality is satisfied then the investment maximizes the (after-tax) level of consumption, whatever the level of exogenous income and whatever the level of tax $T_{a}$ (which is exogenous for consumer too). Finally an unchanged level of $s$ also implies that emissions (i.e. gross pollution) are unchanged. The policy reduces however environmental degradation (i.e. net pollution).

31 A very simple example of the kind of policy introduced in this section can be, for instance, a public intervention (financed by a lump sum tax) which plants new trees.

32 A linear abatement is used for instance by Economides and Philippopoulos (2008) and by Gupta and Barman (2009). 
the following problem

$$
\max _{T_{a}} U\left(y-s^{\star}+f\left(s^{\star}\right)-T_{a}, q_{0}-g\left(s^{\star}\right)+m T_{a}\right) .
$$

The first-order condition of this problem is ${ }^{33}$

$$
\begin{aligned}
& -U_{c}\left(y-s^{\star}+f\left(s^{\star}\right)-\overline{T_{a}}, q_{0}-g\left(s^{\star}\right)+m \overline{T_{a}}\right) \\
& \quad+m U_{q}\left(y-s^{\star}+f\left(s^{\star}\right)-\overline{T_{a}}, q_{0}-g\left(s^{\star}\right)+m \overline{T_{a}}\right)=0 .
\end{aligned}
$$

where $\overline{T_{a}}$ is the optimal abatement tax.

In this context, we can introduce two alternative types of environmental risk: 'risk on environmental quality level' ( $q_{0}$ random) or 'risk on the effect of the abatement policy' ( $m$ random).

(a) Risk on environmental quality

First we study the case when $q_{0}$ is random. We define it as $\widetilde{q}_{0}$ and its expected value as $\mathbb{E}\left(\tilde{q}_{0}\right)=q_{0}$. We also denote as $\tilde{T}_{a}$ the abatement tax under risk. Under risk the previous maximisation problem becomes

$$
\max _{T_{a}} \mathbb{E}\left[U\left(y-s^{\star}+f\left(s^{\star}\right)-T_{a}, \tilde{q}_{0}-g\left(s^{\star}\right)+m T_{a}\right)\right] .
$$

The first-order condition is now

$$
\begin{aligned}
& -\mathbb{E}\left[U_{c}\left(y-s^{\star}+f\left(s^{\star}\right)-\tilde{T}_{a}, \tilde{q}_{0}-g\left(s^{\star}\right)+m \tilde{T}_{a}\right)\right] \\
& +m \mathbb{E}\left[U_{q}\left(y-s^{\star}+f\left(s^{\star}\right)-\tilde{T}_{a}, \tilde{q}_{0}-g\left(s^{\star}\right)+m \tilde{T}_{a}\right)\right]=0 .
\end{aligned}
$$

Comparing (11) and (12) we have

Proposition 3 Under risk on environmental quality level, conditions $U_{c q q} \leq(\geq) 0$ and $U_{q q q} \geq(\leq) 0$ are sufficient to have $\tilde{T}_{a} \geq(\leq) \overline{T_{a}}$.

Proof See Appendix B.

The sufficient conditions in Proposition 3 are the same as Proposition 1, and their interpretation is similar too. Conditions $U_{c q q} \leq 0$ and $U_{q q q} \geq 0$ ensure that the disutility due to risk is reduced when consumption decreases and environmental quality is improved. This implies that we choose larger abatement under risk.

(b) Risk on the impact of abatement policy

We now study the second type of risk: risk on the effect of abatement policy. We thus consider $m$ random and we denote it as $\tilde{m}$ and its expected value $E(\tilde{m})$ as $m$. In this

\footnotetext{
33 The second-order condition for this problem is $U_{c c}\left(y-s^{\star}+f\left(s^{\star}\right)-T_{a}, q_{0}-g\left(s^{\star}\right)+m T_{a}\right)-$ $2 m U_{c q}\left(y-s^{\star}+f\left(s^{\star}\right)-T_{a}, q_{0}-g\left(s^{\star}\right)+m T_{a}\right)+m^{2} U_{q q}\left(y-s^{\star}+f\left(s^{\star}\right)-T_{a}, q_{0}-g\left(s^{\star}\right)+m T_{a}\right)<0$. Given our assumption on $U(c, q)$ it is surely satisfied if $U_{c q} \geq 0$.
} 
case the maximisation problem and the first-order condition become respectively

$$
\max _{T_{a}} \mathbb{E}\left[U\left(y-s^{\star}+f\left(s^{\star}\right)-T_{a}, q_{0}-g\left(s^{\star}\right)+\widetilde{m} T_{a}\right)\right]
$$

and

$$
\begin{aligned}
& -\mathbb{E}\left[U_{c}\left(y-s^{\star}+f\left(s^{\star}\right)-\tilde{T}_{a}, q_{0}-g\left(s^{\star}\right)+\tilde{m} \tilde{T}_{a}\right)\right] \\
& +\mathbb{E}\left[\tilde{m} U_{q}\left(y-s^{\star}+f\left(s^{\star}\right)-\tilde{T}_{a}, q_{0}-g\left(s^{\star}\right)+\tilde{m} \tilde{T}_{a}\right)\right]=0 .
\end{aligned}
$$

Comparing (11) and (13) we have

Proposition 4 Under risk on abatement effect, conditions $U_{c q q} \leq(\geq) 0$ and $-m T_{a} \frac{U_{q q q}}{U_{q q}} \geq(\leq) 2$ are sufficient to have $\tilde{T}_{a} \geq(\leq) \overline{T_{a}}$.

Proof See Appendix B.

Sufficient conditions obtained in this case are similar to those in the case of the effect of risk on pollution. In particular, condition $U_{c q q} \leq 0$ is exactly the same and has an analogous interpretation. Condition $-m T_{a} \frac{U_{q q q}}{U_{q q}} \geq(\leq) 2$ is similar to that obtained in Proposition 2 and is equivalent to that derived by Rothschild and Stiglitz (1971). As explained in Sect. 2, this condition is related to risk on returns, and, consistently, abatement performance (now uncertain) is the return of the abatement policy. Furthermore, unlike the case of $k$ in Sect. 3, return here is positive (policy improves environmental quality level), so the threshold level is exactly the same as determined by Rothschild and Stiglitz (1971).

Finally it should be noted that we introduced the abatement tax as a lump-sum tax. An alternative would be a tax proportional to investments, i.e. that the abatement policy is financed by a tax on the polluting investment. In this case, the term $T_{a}$ in the first argument of planner's utility function would be replaced by the term $s T_{a}$. We emphasized that, although it could be plausible, this alternative is not a completely efficient scheme. In fact, in this case, tax $T_{a}$ has the two aims of reducing investment to its socially optimal level (like the Pigouvian tax of Sect. 3) and financing the optimal abatement on pollution. For this reason, even in the case of certainty, its level would reflect the balance between these different objectives. A more efficient way to pursue the two objectives is to use a specific policy instrument for each: a Pigouvian tax to control investment and a lump-sum tax to finance abatement policies. A model with these two instruments together is studied in Sect. 5.

\section{A Pigouvian tax and abatement policy model}

In this section we introduce both instruments together, using a framework where the policy maker uses both an abatement policy and a Pigouvian tax. In this case, the planner chooses socially optimal levels of investment $(s)$ and abatement policies $\left(T_{a}\right)$, 
solving the following problem

$$
\max _{s, T_{a}} U\left(y-s+f(s)-T_{a}, q_{0}+m T_{a}-k s\right) .
$$

Note that this problem seems similar to that in Sect. 4. The difference between them is that, in the model in this section, $s$ is chosen by the planner (since it is determined by the Pigouvian tax $T_{p}$ ) while, in the model in Sect. 4 , the value of $s$ is exogenously given. The maximisation implies

$$
\begin{aligned}
& -U_{c}\left(y-\bar{s}+f(\bar{s})-\overline{T_{a}}, q_{0}+m \overline{T_{a}}-k \bar{s}\right) \\
& \quad+m U_{q}\left(y-\bar{s}+f(\bar{s})-\overline{T_{a}}, q_{0}+m \overline{T_{a}}-k \bar{s}\right)=0 \\
& U_{c}\left(y-\bar{s}+f(\bar{s})-\overline{T_{a}}, q_{0}+m \overline{T_{a}}-k \bar{s}\right)\left(f^{\prime}(\bar{s})-1\right) \\
& \quad-k U_{q}\left(y-\bar{s}+f(\bar{s})-\overline{T_{a}}, q_{0}+m \overline{T_{a}}-k \bar{s}\right)=0 .
\end{aligned}
$$

From (14) and (15) we get

$$
\frac{U_{c}\left(y-\bar{s}+f(\bar{s})-\overline{T_{a}}, q_{0}+m \overline{T_{a}}-k \bar{s}\right)}{U_{q}\left(y-\bar{s}+f(\bar{s})-\overline{T_{a}}, q_{0}+m \overline{T_{a}}-k \bar{s}\right)}=m
$$

and

$$
\frac{U_{c}\left(y-\bar{s}+f(\bar{s})-\overline{T_{a}}, q_{0}+m \overline{T_{a}}-k \bar{s}\right)}{U_{q}\left(y-\bar{s}+f(\bar{s})-\overline{T_{a}}, q_{0}+m \overline{T_{a}}-k \bar{s}\right)}=\frac{k}{f^{\prime}(\bar{s})-1} .
$$

Given (16) and (17) we have that

$$
f^{\prime}(\bar{s})-1-\frac{k}{m}=0 .
$$

Once the optimal investment $\bar{s}$ is determined by (18), we compute $\overline{T_{a}}$ by substituting it in (14). Finally, given (7), the optimal level of $T_{p}$ is obtained. ${ }^{34}$

Previous conditions clearly indicate a separation of the objectives of Pigouvian tax and abatement policy. Pigouvian tax is used in order to guarantee a level of investment $s$ which satisfies condition (18). The left-hand side of this equation can be seen as the ratio of monetary net marginal positive return of investment $s$ on consumption (which is equal to $\left.f^{\prime}(s)-1\right)$ and monetary marginal cost of abatement policy on consumption (which is equal to 1). The right-hand side is the ratio between the marginal negative effect of pollution due to environment (equal to $k$ ) and the marginal positive effect of abatement policy on environment (equal to the investment $m$ ). This condition can thus be seen as a condition requiring the equality between the 'relative marginal positive return' of the two policies in term of consumption and the 'relative marginal negative effect/cost' of the two policies in terms of environmental quality. The Pigouvian tax

34 Note that (7) still holds since consumer's maximization problem is the same of Sect. 3. 
is thus used for this purpose. Once this efficiency condition is satisfied, we need to balance the effects in terms of utils of the two instruments. This is guaranteed by the optimal choice of $T_{a}$ in (14). Abatement policy is thus focused on this second goal.

Given these premises, we can now introduce different kinds of risk. In this model we can have three types of environmental risk: risk on environmental quality level $\left(q_{0}\right.$ random), risk on the effect of pollution ( $k$ random) and risk on the effect of the abatement policy ( $m$ random). In all three cases, we use notation from previous sections in order to indicate random variables (i.e., $\tilde{q}_{0}, \tilde{m}$ and $\tilde{k}$ ) and we denote as $\tilde{s}, \tilde{T}_{p}$ and $\tilde{T}_{a}$ investment, Pigouvian tax and abatement tax under risk respectively.

(a) Risk on environmental quality

We first examine the case when $q_{0}$ is random. The planner's maximisation problem will be:

$$
\max _{s, T_{a}} \mathbb{E}\left[U\left(y-s+f(s)-T_{a}, \tilde{q}_{0}+m T_{a}-k s\right)\right]
$$

The first-order conditions are

$$
\begin{aligned}
& -\mathbb{E}\left[U_{c}\left(y-\tilde{s}+f(\tilde{s})-\tilde{T}_{a}, \tilde{q}_{0}+m \tilde{T}_{a}-k \tilde{s}\right)\right] \\
& \quad+m \mathbb{E}\left[U_{q}\left(y-\tilde{s}+f(\tilde{s})-\tilde{T}_{a}, \tilde{q}_{0}+m \tilde{T}_{a}-k \tilde{s}\right)\right]=0 \\
& \mathbb{E}\left[U_{c}\left(y-\tilde{s}+f(\tilde{s})-\tilde{T}_{a}, \tilde{q}_{0}+m \tilde{T}_{a}-k \tilde{s}\right)\right]\left(f^{\prime}(\tilde{s})-1\right) \\
& \quad-k \mathbb{E}\left[U_{q}\left(y-\tilde{s}+f(\tilde{s})-\tilde{T}_{a}, \tilde{q}_{0}+m \tilde{T}_{a}-k \tilde{s}\right)\right]=0 .
\end{aligned}
$$

Simple computations show that, in this case, condition (18) still holds, so that

$$
f^{\prime}(\tilde{s})-1-\frac{k}{m}=0
$$

Again, once the optimal investment $\tilde{s}$ is obtained, we compute $\tilde{T}_{a}$ by substituting it in (19). Finally, the level of $\tilde{T}_{p}$ is obtained by (7). By comparing conditions (14), (15), (18) and (19), (20), (21) we have

Proposition 5 Given risk on environmental quality: (a) $\tilde{T}_{p}=\overline{T_{p}}$ and (b) conditions $U_{c q q} \leq(\geq) 0$ and $U_{q q q} \geq(\leq) 0$ are sufficient to have $\tilde{T}_{a} \geq(\leq) \overline{T_{a}}$.

\section{Proof See Appendix B.}

We analyze the interpretation of these results after studying the other types of risk.

(b) Risk on the impact of abatement

When $m$ is random, the maximisation problem becomes

$$
\max _{s, T_{a}} \mathbb{E}\left[U\left(y-s+f(s)-T_{a}, q_{0}+\tilde{m} T_{a}-k s\right)\right]
$$


The first-order conditions are

$$
\begin{aligned}
& -\mathbb{E}\left[U_{c}\left(y-\tilde{s}+f(\tilde{s})-\tilde{T}_{a}, q_{0}+\tilde{m} \tilde{T}_{a}-k \tilde{s}\right)\right] \\
& +\mathbb{E}\left[\tilde{m} U_{q}\left(y-\tilde{s}+f(\tilde{s})-\tilde{T}_{a}, q_{0}+\tilde{m} \tilde{T}_{a}-k \tilde{s}\right)\right]=0 \\
& \mathbb{E}\left[U_{c}\left(y-\tilde{s}+f(\tilde{s})-\tilde{T}_{a}, q_{0}+\tilde{m} \tilde{T}_{a}-k \tilde{s}\right)\right]\left(f^{\prime}(\tilde{s})-1\right) \\
& \quad-k \mathbb{E}\left[U_{q}\left(y-\tilde{s}+f(\tilde{s})-\tilde{T}_{a}, q_{0}+\tilde{m} \tilde{T}_{a}-k \tilde{s}\right)\right]=0 .
\end{aligned}
$$

Simple computations show that in this case, condition (18) is replaced by

$$
f^{\prime}(\tilde{s})-1-\frac{k \mathbb{E}\left[U_{q}\left(y-\tilde{s}+f(\tilde{s})-\tilde{T}_{a}, q_{0}+\tilde{m} \tilde{T}_{a}-k \tilde{s}\right)\right]}{\mathbb{E}\left[\tilde{m} U_{q}\left(y-\tilde{s}+f(\tilde{s})-\tilde{T}_{a}, q_{0}+\tilde{m} \tilde{T}_{a}-k \tilde{s}\right)\right]}=0 .
$$

As before, once the optimal investment $\tilde{s}$ is obtained, we compute $\tilde{T}_{a}$ by substituting it in (22). Finally, the level of $\tilde{T}_{p}$ is obtained by (7). By comparing conditions (14), (15), (18) and (22), (23) and (24) we get

Proposition 6 Given risk on abatement, (a) $\tilde{T}_{p}>\overline{T_{p}}$ and (b) conditions $U_{c q q} \geq 0$ and $U_{q q q} \leq 0$ are sufficient to have $\tilde{T}_{a}<\overline{T_{a}}$.

Proof See Appendix B.

In this case too, the interpretation of the proposition is provided below.

(c) Risk on the effect of pollution

Finally we examine the case where $k$ is random. In this case, the maximisation problem becomes

$$
\max _{s, T_{a}} \mathbb{E}\left[U\left(y-s+f(s)-T_{a}, q_{0}+m T_{a}-\tilde{k} s\right)\right] .
$$

The first-order conditions are

$$
\begin{aligned}
& -\mathbb{E}\left[U_{c}\left(y-\tilde{s}+f(\tilde{s})-\tilde{T}_{a}, q_{0}+m \tilde{T}_{a}-\tilde{k} \tilde{s}\right)\right] \\
& \quad+m \mathbb{E}\left[U_{q}\left(y-\tilde{s}+f(\tilde{s})-\tilde{T}_{a}, q_{0}+m \tilde{T}_{a}-\tilde{k} \tilde{s}\right)\right]=0 \\
& \mathbb{E}\left[U_{c}\left(y-\tilde{s}+f(\tilde{s})-\tilde{T}_{a}, q_{0}+m \tilde{T}_{a}-\tilde{k} \tilde{s}\right)\right]\left(f^{\prime}(\tilde{s})-1\right) \\
& -\quad \mathbb{E}\left[\tilde{k} U_{q}\left(y-\tilde{s}+f(\tilde{s})-\tilde{T}_{a}, q_{0}+m \tilde{T}_{a}-\tilde{k} \tilde{s}\right)\right]=0 .
\end{aligned}
$$

Simple computations show that in this case condition (18) is replaced by

$$
f^{\prime}(\tilde{s})-1-\frac{\mathbb{E}\left[\tilde{k} U_{q}\left(y-\tilde{s}+f(\tilde{s})-\tilde{T}_{a}, q_{0}+m \tilde{T}_{a}-\tilde{k} \tilde{s}\right)\right]}{m \mathbb{E}\left[U_{q}\left(y-\tilde{s}+f(\tilde{s})-\tilde{T}_{a}, q_{0}+m \tilde{T}_{a}-\tilde{k} \tilde{s}\right)\right]}=0 .
$$


As in the previous cases, once the optimal investment $\tilde{s}$ is obtained, we compute $\tilde{T}_{a}$ by substituting in (25). Finally, the level of $\tilde{T}_{p}$ is obtained by (7). By comparing conditions (14), (15), (18) and (25), (26), (27) we have

Proposition 7 Given risk on the pollution effect, (a) $\tilde{T}_{p}>\overline{T_{p}}$ and (b) conditions $U_{c q q} \geq 0$ and $U_{q q q} \leq 0$ are sufficient to have $\tilde{T}_{a}<\overline{T_{a}}$.

\section{Proof See Appendix B.}

Propositions 5, 6 and 7 show the effects on $q_{0}, k$ and $m$ respectively under risk. Considering them together, we can now interpret the conclusions obtained. We start by considering $T_{p}$. As we mentioned, the Pigouvian tax is used by the planner in order to guarantee the equality between the relative marginal positive return in terms of consumption and the relative marginal negative effect/cost in terms of pollution of the two policies. This fact justifies the different results obtained in point (a) of Propositions 5, 6 and 7.

In fact, when $q_{0}$ is random, risk affects neither marginal returns of the policies nor their marginal costs. This implies that, the choice of $T_{p}$ in this case is the same as the one under certainty.

On the contrary, when $k$ is random, we have that the expected marginal cost of pollution rises (See the role of the covariance in the proof of Proposition 7). The increase in the expected marginal cost requires an increase in marginal return of investment. This implies in turn a smaller $s$ and a larger $T_{p}$.

Similarly, when $m$ is random, the expected marginal abatement performance decreases (See the role of the covariance in the proof of Proposition 6) becoming smaller than the expected marginal cost. This also requires an increase in marginal return of investment in order to recover the equality between relative marginal return and relative marginal cost. This implies in turn a smaller $s$ and a larger $T_{p}$.

Consider now the effect on $T_{a}$. As shown at the beginning of this section, $T_{a}$ is used in order to guarantee the balance of the effect of the two instruments used by the planner in terms of utils. Whatever the type of risk, $q_{0}, k$ or $m$, this balance cannot be guaranteed by the pair of values, $\overline{T_{p}}, \overline{T_{a}}$, since the disutility due to risk must somehow be counteracted.

As shown before, when $q_{0}$ is random, the value of $T_{p}$ does not change. This implies that the disutility due to risk must be totally counteracted by the change in $T_{a}$. Given this conclusion, change in the value of $T_{a}$ depends on the features of the third-order derivatives of the utility function, for the reasons explained in the comment to Proposition 1.

When either $k$ or $m$ is random, the picture is more complicated. In fact, as shown before, in these two cases, the level of $T_{p}$ increases. This obviously has an effect on marginal utility. When $U_{c q q} \geq 0$ and $U_{q q q} \leq 0$, the change of $T_{p}$ strengthens the effect of disutility due to risk. So the level of $T_{a}$ must surely decrease in order to counteract it. When $U_{c q q} \leq 0$ and $U_{q q q} \geq 0$, on the other hand, the increase in $T_{p}$ counteracts the effect of the disutility due to risk. This implies that, in general, we cannot say if $T_{a}$ has to increase, decrease or remain unchanged. This last reasoning explains the asymmetry in the inequalities in Propositions 6 (b) and 7 (b) with regard to the results in the previous propositions. 


\section{Generalization to the $N$-th order risk changes}

In the previous sections we considered three kinds of risk related to variables $q_{0}, k$ and $m$. In particular, we compared the optimal choice when one of these variables is certain with the optimal choice when the same variable is random, under the assumption that the expected value of the variable in the uncertainty case is equal to the given value of the variable in the certainty case. This means that the comparison is in fact a comparison between two random variables with same expected value and different variance (zero in one case, positive in the other). It can thus be interpreted as a change in the second-order moment of the distribution of the random variable given the first-order moment.

This interpretation is relevant if it is related to a taxonomy of risk changes first introduced by Ekern (1980) and recently reconsidered by Eeckhoudt and Schlesinger (2008). In particular, Ekern (1980) introduced the general concepts of $N$-th degree stochastic dominance and $N$-th degree increase in risk, related to an increase in the $N$-th moment of a risky distribution, given the invariance of the $N-1$ previous moments. Formal definitions of the concepts of $N$-th degree stochastic dominance and $N$-th degree increase in risk are as follows.

Let $F$ and $G$ be the cumulative distribution of the two random variables $\tilde{y}$ and $\tilde{x}$, defined on a probability support contained within an open interval $(a, b)$. Define $F_{1}=F, G_{1}=G, F_{n+1}(x)=\int_{a}^{x} F_{n}(t) d t$ for $n \geq 1$ and similarly define $G_{n+1}$. Given these definitions, $\tilde{y}$ dominates $\widetilde{x}$ via $N$-th degree stochastic dominance if $F_{N}(x) \leq$ $G_{N}(x) \forall x$ and $F_{n}(b) \leq G_{n}(b)$ for $n=1, \ldots, N-1$. Furthermore $\tilde{x}$ is defined as an increase in $N$-th degree risk over $\tilde{y}$ if $\tilde{y}$ dominates $\tilde{x}$ via $N$-th degree stochastic dominance and the first $N-1$ moments of the distributions of $\widetilde{y}$ and $\widetilde{x}$ coincide.

It is clear that in this framework the comparisons presented in previous sections are second-degree risk changes. This suggests that the previous results can be generalized to the case of a $\mathrm{N}$-th degree risk change. In particular, Eeckhoudt and Schlesinger (2008) provide a characterisation of $N$-th degree risk changes related to the sign of the derivates until order $N$ of an expected univariate utility function. In a recent paper, Chiu and Eeckhoudt (2010) generalise these results to the case of a bivariate utility. Their characterisation can be summarised as follows ${ }^{35}$

Lemma 8 Defining $U_{(i),(j)}$ as the $i$-th order partial derivate with regard to the first argument and the $j$-th order partial derivate with regard to the second argument of $U(.$, .), we have that

(a) for $\tilde{x}$ being an $N$-th degree risk increase over $\tilde{y}, \mathbb{E} U(a, \tilde{x}) \leq(\geq) \mathbb{E} U(a, \tilde{y})$ if and only if $(-1)^{N} U_{(0),(N)} \leq(\geq) 0$;

(b) for $\tilde{y}$ dominating $\tilde{x}$ via $N$-th degree stochastic dominance, $\mathbb{E} U(a, \tilde{x}) \leq(\geq)$ $\mathbb{E} U(a, \tilde{y})$ if and only if $(-1)^{n} U_{(0),(n)} \leq(\geq) 0$ for all $n=1,2, \ldots, N$.

This Lemma can be used to generalise some from the results in the previous sections. Letting $T_{p}\left(\tilde{q_{1}}\right), T_{a}\left(\tilde{q_{1}}\right)$ and $s\left(\tilde{q_{1}}\right)$ as the optimal level of $T_{p}, T_{a}$ and $s$ given

\footnotetext{
35 Our Lemma reproduces Lemma 1 by Chiu and Eeckhoudt (2010). See, for instance, Ingersoll (1987) for the proof.
} 
$q_{0}=\tilde{q_{1}}, T_{p}\left(\tilde{q_{2}}\right), T_{a}\left(\tilde{q_{2}}\right)$ and $s\left(\tilde{q_{2}}\right)$ as the optimal level of $T_{p}, T_{a}$ and $s$ given $q_{0}=\tilde{q_{2}}$, $T_{p}\left(\tilde{m}_{1}\right), T_{a}\left(\tilde{m}_{1}\right)$ and $s\left(\tilde{m}_{1}\right)$ as the optimal level of $T_{p}, T_{a}$ and $s$ given $m=\tilde{m}_{1}, T_{p}\left(\tilde{m}_{2}\right)$, $T_{a}\left(\tilde{m}_{2}\right)$ and $s\left(\tilde{m}_{2}\right)$ as the optimal level of $T_{p}, T_{a}$ and $s$ given $m=\tilde{m_{2}}, T_{p}\left(\tilde{k_{1}}\right), T_{a}\left(\tilde{k_{1}}\right)$ and $s\left(\tilde{k_{1}}\right)$ as the optimal level of $T_{p}, T_{a}$ and $s$ given $k=\tilde{k_{1}}$, and finally $T_{p}\left(\tilde{k_{2}}\right), T_{a}\left(\tilde{k_{2}}\right)$ and $s\left(\tilde{k_{2}}\right)$ as the optimal level of $T_{p}, T_{a}$ and $s$ given $k=\tilde{k_{2}}$, we have:

Proposition 9 Assume $q_{0}$ random and that $\widetilde{q_{2}}$ is an $N$-th degree risk increase of $\widetilde{q_{1}}$. Conditions $(-1)^{N} U_{(0),(N+1)} \geq(\leq) 0$ and $(-1)^{N} U_{(1),(N)} \leq(\geq) 0$ are sufficient for

(a) $T_{p}\left(\tilde{q_{2}}\right) \geq(\leq) T_{p}\left(\tilde{q_{1}}\right)$ in Pigouvian tax model (Sect. 3);

(b) $T_{a}\left(\tilde{q_{2}}\right) \geq(\leq) T_{a}\left(\tilde{q_{1}}\right)$ in abatement policy model (Sect. 4$)$.

Proof See Appendix B.

Corollary 10 Assume $q_{0}$ random and that $\tilde{q}_{1}$ dominates $\tilde{q}_{2}$ via $N$-th degree stochastic dominance. Conditions $(-1)^{n} U_{(0),(n+1)} \geq(\leq) 0$ and $(-1)^{n} U_{(1),(n)} \leq(\geq) 0$ for $n=1, \ldots, N$ are sufficient for (a) and (b) in Proposition 9.

Proof See Appendix B.

Proposition 11 Assume $m$ random and that $\tilde{m}_{2}$ is an $N$-th degree risk increase of $\tilde{m}_{1}$. Conditions $-m T_{a} \frac{U_{(0),(N+1)}}{U_{(0),(N)}} \geq(\leq) N$ and $(-1)^{N} U_{(1),(N)} \leq(\geq) 0$ are sufficient for $T_{a}\left(\tilde{m}_{2}\right) \geq(\leq) T_{a}\left(\tilde{m}_{1}\right)$ in the abatement policy model (Sect. 4$)$.

Proof See Appendix B.

Corollary 12 Assume $m$ random and that $\tilde{m}_{1}$ dominates $\tilde{m}_{2}$ via $N$-th degree stochastic dominance. Conditions $-m T_{a} \frac{U_{(0),(n+1)}}{U_{(0),(n)}} \geq(\leq) n$ and $(-1)^{n} U_{(1),(n)} \leq(\geq) 0$ for all $n=1, \ldots, N$ are sufficient for $T_{a}\left(\tilde{m}_{2}\right) \geq(\leq) T_{a}\left(\tilde{m}_{1}\right)$ in the abatement policy model (Sect. 4).

Proof See Appendix B.

Proposition 13 Assume $k$ random and that $\tilde{k_{2}}$ is an $N$-th degree risk increase of $\tilde{k_{1}}$. Conditions $(-1)^{N} k s \frac{U_{(0),(N+1)}}{U_{(0),(N)}} \leq(\geq)(-1)^{N} N$ and $(-1)^{N} U_{(1),(N)} \leq(\geq) 0$ are sufficient for $T_{p}\left(\tilde{k_{2}}\right) \geq(\leq) T_{p}\left(\tilde{k_{1}}\right)$ in the Pigouvian tax model (Sect. 3).

Proof See Appendix B.

Corollary 14 Assume $k$ random and that $\tilde{k_{1}}$ dominates $\tilde{k}_{2}$ via $N$-th degree stochastic dominance. Conditions $(-1)^{n}(k s) \frac{U_{(0),(n+1)}}{U_{(0),(n)}} \leq(\geq)(-1)^{n} n$ and $(-1)^{n} U_{(1),(n)} \leq(\geq) 0$ are sufficient for $T_{p}\left(\tilde{k_{2}}\right) \geq(\leq) T_{p}\left(\tilde{k_{1}}\right)$ for all $n=1, \ldots, N$ in Pigouvian tax model (Sect. 3).

Proof See Appendix B. 
Propositions 9, 11 and 13 generalise some results obtained in the previous sections. Note that this generalisation does not involve the results obtained in the model with both Pigouvian tax and abatement policy. This is because we cannot generalise the conclusions on the changes of $T_{p}$ obtained in this model, specifically related to the sign of covariances, to an $N$-th order risk change.

Once the generalisation is performed, it has various possible applications. The literature on risks provides the interpretation of risk changes of many different orders. ${ }^{36}$ Some of these interpretations can be simply applied to the case of risk on the environment.

First, consider the case of a first-degree increase in risk $(N=1$ in the previous propositions) and assume $q_{0}$ is random. This is a situation where we consider a reduction in first-order moment of the distribution of $\widetilde{q}_{0}$. This occurs for example if climate change implies a lower expected environmental quality. ${ }^{37}$

Second, consider the case of a third-degree increase in risk $(N=3$ in the previous propositions) and assume again $q_{0}$ is random. Menezes et al. (1980) study a third-degree risk increase as a downside risk increase, i.e. as a increase in the left skewness of a distribution. ${ }^{38}$ In our framework, a case of a third-degree increase in risk in $\widetilde{q}_{0}$, could thus be seen as an increase in the probability of very bad outcomes in environmental quality, for given expected value and variance of $\widetilde{q}_{0} \cdot{ }^{39}$

Finally, consider a fourth degree risk increase case $(N=4$ in the previous proposition). In this case, for given expected value, variance and skewness we have an increase in the kurtosis of the distribution (see Menezes and Wang 2005). For example, this could be climate change which affects temperature level determining an increase in the probability of high and low temperatures, but keeping constant the expected value, the variance and the skewness of the temperature distribution. ${ }^{40}$

These considerations show how the results in Proposition 9, 11 and 13 generalize the conclusions in the previous sections. Sections 3, 4 and 5 study policy reaction when we introduce environmental risk, i.e. in case of a change in the variance of environmental quality, pollution effect or abatement effect. The results in this section analyze this reaction when the change occurs in other moments of the random variables describing environmental risks, such as skewness and kurtosis or even higher-order moments. Propositions 9, 11 and 13 show that the conclusions derived in these cases

\footnotetext{
36 On this see Menezes et al. (1980), Menezes and Wang (2005), Eeckhoudt and Schlesinger (2006, 2008).

37 Eeckhoudt and Schlesinger (2008), who study a two-period consumption problem, suggest that a firstdegree risk change can occur in that framework when the probability of becoming unemployed increases, reducing future expected income. Similarly, in our case, a first-degree risk change can occur when the probability of an environmental accident increases, and future expected environmental quality is lowered.

38 Menezes et al. (1980) show that this can be obtained by applying a mean preserving spread and a mean preserving contraction with specific feature.

39 Note that, in a very recent paper, Pindyck (2009) studies the economic impact of global warming, considering not the expected climate change but the implications of the different features of the distribution of the random variable describing future changes in temperature (represented by a three-parameter gamma distribution). His calibrations show that a change in the skewness of the distribution for given expected value and variance (i.e. a third-degree change in risk) can significantly affect agents optimal behaviour.

40 With regard to the implications of a large kurtosis, see also the discussion on the 'Dismal Theorem' in the Conclusions.
} 
involve conditions which are similar to those of the case where variance changes but pertain to higher-order derivates of the utility function.

\section{Conclusions}

This paper studies the implication of three kinds of environmental risk: risk on environmental quality, risk on the effect of pollution and risk on the impact of abatement for two different environmental policies (Pigouvian tax and abatement policy) used either alternatively or contemporaneously.

In the two cases where we use either Pigouvian tax or abatement policy, we determine the conditions ensuring that the introduction of risk brings about an increase in the size of public intervention (a higher Pigouvian tax or a larger abatement) and vice versa. In the case of risk on environmental quality, these conditions involve the signs of two third-order derivatives of the utility function $\left(U_{q q q}\right.$ and $\left.U_{c q q}\right)$. The results for $U_{q q q}$ are linked to a wide strand of literature, starting from Leland (1968), Sandmo (1970) and Kimball (1990), showing the role of prudence for precautionary saving in a one-argument utility framework. ${ }^{41}$ Similarly, the role of $U_{c q q}$ in decisions under risk has recently been emphasized by many papers (e.g. Courbage and Rey 2007; Menegatti 2009a,b; Denuit et al. 2011; Chiu and Eeckhoudt 2010) which consider a two-argument utility. In this field, our conclusions confirm the role of third-order cross derivatives of the utility function in the determination of optimal choices under risk. Furthermore, the interpretation of the conditions obtained shows that, as in the case of precautionary saving analysis (see Menegatti 2007; Eeckhoudt and Schlesinger 2006), the reason that the signs of these derivates are relevant is their ability to indicate the direction of the effect on the disutility due to risk of change in consumption level or environmental quality.

The effects of risk on pollution impact and abatement impact (either Pigouvian tax or abatement policy) are, on the other hand, shown to depend on the size of relative prudence. This result is consistent with those obtained by Rothschild and Stiglitz (1971) in the field of optimal saving under risk on the interest rate (the return of saving) and by Chiu and Eeckhoudt (2010) in the field of optimal labour supply under risk on wage (the return of labour). We showed that this parallelism occurs, because in our analysis risk involves two kinds of returns: the positive return of abatement policy or the negative return of investment in terms of pollution.

When Pigouvian tax and abatement policy are used together we have a kind of separation of the two policy instruments. In particular, the Pigouvian tax is used to guarantee equality between the relative marginal positive return in terms of consumption and the relative marginal negative effect/cost in terms of pollution of the two policies. This implies that the Pigouvian tax level is increased by risk on both pollution effect and abatement effect, since the former raises the expected marginal cost of pollution and the latter reduces the expected marginal return of investment. Finally, risk on environmental quality affects neither expected marginal returns nor expected marginal costs of the two policies, so that it does not influence Pigouvian tax.

\footnotetext{
41 Recently prudence was also proved to be crucial in the determination of optimal prevention (see Eeckhoudt and Gollier 2005; Menegatti 2009c).
} 
Again, when Pigouvian tax and abatement policy are used together, the abatement policy is applied in order to guarantee the balance between the effects of the two policy instruments in terms of utils and thus also counteracts the disutility caused by risk. When environmental quality is uncertain, given that the Pigouvian tax does not change, abatement tax is the only instrument used to counteract the disutility due to risk. It thus exhibits a change in a direction clearly determined by the features of the third-order derivatives of the utility function. When risk is on either pollution effect or abatement effect, the level of Pigouvian tax increases, so that a clear indication on the change of the abatement tax can be obtained only where the change in Pigouvian tax strengthens the disutility due to risk, making necessary an increment in the level of the other instrument.

The last part of the paper shows how some of our results can be generalized to the case of $N$-th order risk change. This kind of shock, first studied by Ekern (1980), has recently been rediscovered by literature (e.g. Eeckhoudt and Schlesinger 2006, 2008) because of its applicability to cases of change in random variables distribution other than increases in variance. Our analysis shows which conditions, involving $N$-th order derivatives of the utility function, allow us to determine the directions of the effects of these shocks on some optimal policy choices.

Finally, it is important to note that our results can be interpreted in two different ways. On one hand, they provide a clear indication of the way policy variables change under risk once the features of the planner's utility function are determined. In this field thus, given preferences, we obtain conclusions on the impact of environmental risk on optimal policies. On the other hand, the results also allow us to compare the implications of different utility functions in terms of response to environmental risk. In this field they are thus useful for the selection of models describing preferences.

This last conclusion is particularly relevant in the light of the debate on the implication of Weitzman's (2009a, b, c) Dismal Theorem for the analysis of climate change. Weitzman argues that structural uncertainty, characterising global warming, implies fat tails for the distribution of risk related to climate change. He also shows that the combination of an heavy-tailed distribution and a large but specific class of utility function (the family of power utilities, largely used in economic models) implies fragility of the expected utility theory. ${ }^{42}$ Leaving aside the debate on the plausibility of Weitzman premise on the distribution of risk due to global warming, ${ }^{43}$ which lies outside the scope of this paper, one implication of Weitzman's critique is that, in the analysis of long-run cost and benefit of environmental policies, we should use specifications different from the standard ones. This pertains to various aspects of cost-benefit models, including the form of the utility function. For this reason, one of the possible solutions for Weitzman's critique is to replace power utility functions with functions

\footnotetext{
$\overline{42}$ In particular Geweke (2001) proves this result for CRRA utility function. Weitzman (2009a) claims that this should be applied to every power utility functions where the relative risk aversion coefficient is positive, even if it is not constant for a change in the consumption level. Finally Nordhaus (2009) argues that a necessary condition for the fragility of the expected utility theory is that marginal utility tends to $+\infty$ when consumption tends to zero.

43 On this issue see Nordhaus (2009) and Weitzman (2009c).
} 
from a different family. In this field, our results, derived for a generic utility function, are not only immune from difficulties inherent in a power utility but can also help in the selection among utility functions different from that one, by providing general indications on its desired features.

Acknowledgments We would like to thank three anonymous referees and the participants in seminars at University of Parma and University of Pavia for their useful comments and suggestions.

\section{Appendix A. Risk neutrality versus risk aversion}

The focus of this paper on the comparison between optimal policy choices with and without uncertainty led us to analyze a framework where we assumed that preferences exhibit risk aversion (and in particular aversion to environmental risk). This appendix re-examines the model dealing with both abatement policy and a Pigouvian tax as in Sect. 5 considering the case of risk neutral preferences and compares the risk aversion and risk neutrality results where possible.

Since all the three kinds of risk discussed in this work pertain to the environment, the assumption of risk neutrality can be introduced by describing planner's preferences by means of a utility function which is separable and linear in the argument representing environmental quality. This utility function is thus

$$
U\left(y-s+f(s)-T_{a}\right)+\alpha\left(q_{0}-k s+m T_{a}\right)
$$

where $U^{\prime}>0$ and $U^{\prime \prime}<0$. Note that, since we have no risk on consumption, this last assumption does not describe risk aversion and simply pertains to substitutability between consumption and environmental quality.

Given this utility function, we consider the planner's maximization problem in the four cases studied in Sect. 5: certainty, risk on environmental quality ( $q_{0}$ random), risk on abatement effect ( $m$ random) and risk on pollution ( $k$ random). Planner's maximization problems in the four cases are respectively

$$
\begin{aligned}
& \max _{s, T_{a}} U\left(y-s+f(s)-T_{a}\right)+\alpha\left(q_{0}-k s+m T_{a}\right) \\
& \max _{s, T_{a}} \mathbb{E}\left[U\left(y-s+f(s)-T_{a}\right)+\alpha\left(\tilde{q_{0}}-k s+m T_{a}\right)\right] \\
& \quad=\max _{s, T_{a}} U\left(y-s+f(s)-T_{a}\right)+\alpha\left(\mathbb{E}\left[\tilde{q_{0}}\right]-k s+m T_{a}\right) \\
& \max _{s, T_{a}} \mathbb{E}\left[U\left(y-s+f(s)-T_{a}\right)+\alpha\left(q_{0}-k s+\tilde{m} T_{a}\right)\right] \\
& \quad=\max _{s, T_{a}} U\left(y-s+f(s)-T_{a}\right)+\alpha\left(q_{0}-k s+\mathbb{E}[\tilde{m}] T_{a}\right) \\
& \max _{s, T_{a}} \mathbb{E}\left[U\left(y-s+f(s)-T_{a}\right)+\alpha\left(q_{0}-\tilde{k} s+m T_{a}\right)\right] \\
& \quad=\max _{s, T_{a}} U\left(y-s+f(s)-T_{a}\right)+\alpha\left(q_{0}-\mathbb{E}[\tilde{k}] s+m T_{a}\right) .
\end{aligned}
$$


First-order conditions for problem (28) implies (after some computations):

$$
\begin{gathered}
f^{\prime}(s)-1=\frac{k}{m} \\
U^{\prime}\left(y-s+f(s)-T_{a}\right)=\alpha m .
\end{gathered}
$$

First-order conditions for problem (29) implies:

$$
\begin{gathered}
f^{\prime}(s)-1=\frac{k}{m} \\
U^{\prime}\left(y-s+f(s)-T_{a}\right)=\alpha m .
\end{gathered}
$$

First-order conditions for problem (30) implies:

$$
\begin{gathered}
f^{\prime}(s)-1=\frac{k}{\mathbb{E}[\tilde{m}]} \\
U^{\prime}\left(y-s+f(s)-T_{a}\right)=\alpha \mathbb{E}[\tilde{m}] .
\end{gathered}
$$

Finally, first-order conditions for problem (31) implies:

$$
\begin{gathered}
f^{\prime}(s)-1=\frac{\mathbb{E}[\tilde{k}]}{m} \\
U^{\prime}\left(y-s+f(s)-T_{a}\right)=\alpha m .
\end{gathered}
$$

Since, by assumption, $\mathbb{E}[\tilde{m}]=m$ and $\mathbb{E}[\tilde{k}]=k$. It is easy to see that (32), (34), (36) and (38) are equivalent and that (33), (35), (37) and (39) are equivalent. This provides a first result. The risk neutral planner chooses the same level of $T_{p}$ and $T_{a}$ in the certainty case and in the cases of the three kind of risks analysed.

Furthermore, if we consider this result together with those in Sect. 5, we get a second conclusion. The risk neutral planner and the risk averse planner choose the same level for $T_{p}$ in the certainty case and in the case of risk on environmental quality. The risk averse planner chooses a level of $T_{p}$ larger than that chosen by the risk neutral planner in the cases of risks on pollution effect and on abatement effect.

Finally, no clear conclusion can be drawn with reference to the comparison of optimal levels of $T_{a}$ between the risk averse planner and the risk neutral planner, since the results on this comparison depend on the form of function $U(c, q)$ (and in particular on its derivate $U_{q}$ ).

\section{Appendix B. Proofs}

Proof of Proposition 1 In order to compare $\overline{T_{p}}$ and $\tilde{T}_{p}$ we start by comparing $\bar{s}$ and $\tilde{s}$. To do this we substitute $\bar{s}$ in the left-hand side of the first-order condition (8) (where $\tilde{s}$ is determined). We thus obtain $\mathbb{E}\left[U_{c}\left(y-\bar{s}+f(\bar{s}), \tilde{q}_{0}-g(\bar{s})\right)\right]\left(f^{\prime}(\bar{s})-1\right)-$ $\mathbb{E}\left[U_{q}\left(y-\bar{s}+f(\bar{s}), \tilde{q}_{0}-g(\bar{s})\right)\right] g^{\prime}(\bar{s})$. By Jensen's inequality and since by assumption $\mathbb{E}\left(\tilde{q_{0}}\right)=q_{0}, U_{c q q} \leq 0$ implies $\mathbb{E}\left[U_{c}\left(y-\bar{s}+f(\bar{s}), \tilde{q_{0}}-g(\bar{s})\right)\right] \leq U_{c}(y-\bar{s}+$ 
$\left.f(\bar{s}), q_{0}-g(\bar{s})\right)$ and $U_{q q q} \geq 0$ implies $\mathbb{E}\left[U_{q}\left(y-\bar{s}+f(\bar{s}), \tilde{q_{0}}-g(\bar{s})\right)\right] \geq$ $U_{q}\left(y-\bar{s}+f(\bar{s}), q_{0}-g(\bar{s})\right)$. These results, together with (4), imply that

$$
\begin{aligned}
& \mathbb{E}\left[U_{c}\left(y-\bar{s}+f(\bar{s}), \tilde{q}_{0}-g(\bar{s})\right)\right]\left(f^{\prime}(\bar{s})-1\right) \\
& \quad-\mathbb{E}\left[U_{q}\left(y-\bar{s}+f(\bar{s}), \tilde{q}_{0}-g(\bar{s})\right)\right] g^{\prime}(\bar{s}) \leq 0 .
\end{aligned}
$$

By the second-order condition we know that $\frac{\partial^{2} U}{\partial s^{2}}<0$ implying in turn that the lefthand side of (8) is decreasing in $s$. This, together with (40) implies $\tilde{s} \leq \bar{s}$. Now, given this result, we compare $\overline{T_{p}}$ and $\tilde{T}_{p}$. Since $f^{\prime \prime}(s)<0$, the function $f^{\prime}(s)$ in (7) is decreasing in $s$. This, together with $\tilde{s} \leq \bar{s}$, implies $\tilde{T}_{p} \geq \overline{T_{p}}$. The proof with reversed inequalities is analogous.

Proof of Proposition 2 We first compare $\bar{s}$ and $\tilde{s}$. To do this we substitute $\bar{s}$ in the lefthand side of (10) obtaining $\mathbb{E}\left[U_{c}\left(y-\bar{s}+f(\bar{s}), q_{0}-\tilde{k} \bar{s}\right)\right]\left(f^{\prime}(\bar{s})-1\right)-\mathbb{E}\left[\tilde{k} U_{q}(y-\bar{s}+\right.$ $\left.\left.f(\bar{s}), q_{0}-\tilde{k} \bar{s}\right)\right]$. By Jensen's inequality and since by assumption $\mathbb{E}(\tilde{k})=k, U_{c q q} \leq 0$ implies

$$
\mathbb{E}\left[U_{c}\left(y-\bar{s}+f(\bar{s}), q_{0}-\tilde{k} \bar{s}\right)\right] \leq U_{c}\left(y-\bar{s}+f(\bar{s}), q_{0}-k \bar{s}\right)
$$

Again, by Jensen's inequality,

$$
\mathbb{E}\left[\tilde{k} U_{q}\left(y-\bar{s}+f(\bar{s}), q_{0}-\tilde{k} \bar{s}\right)\right] \geq k U_{q}\left(y-\bar{s}+f(\bar{s}), q_{0}-k \bar{s}\right)
$$

if the function $\Psi(k)=k U_{q}\left(y-s+f(s), q_{0}-k s\right)$ is convex with respect to $k$. After simple calculus we find that $\Psi^{\prime \prime}(k)=-2 s U_{q q}+s^{2} k U_{q q q} \geq 0$, which (since $U_{q q}<0$ ) is equivalent to $-k s \frac{U_{q q q}}{U_{q q}} \geq-2$. This means that $U_{c q q} \leq 0$ and $-k s \frac{U_{q q q}}{U_{q q}} \geq-2$ imply (41) and (42). Inequalities (41) and (42) together with (9), imply that

$$
\mathbb{E}\left[U_{c}\left(y-\bar{s}+f(\bar{s}), q_{0}-\tilde{k} \bar{s}\right)\right]\left(f^{\prime}(\bar{s})-1\right)-\mathbb{E}\left[\tilde{k} U_{q}\left(y-\bar{s}+f(\bar{s}), q_{0}-\tilde{k} \bar{s}\right)\right] \leq 0 .
$$

By the second-order condition, ensuring that the left-hand side of (10) is decreasing in $s$, (43) implies that $\tilde{s} \leq \bar{s}$. Finally, since $f^{\prime}(s)$ in (7) is decreasing in $s, \tilde{s} \leq \bar{s}$ implies $\tilde{T}_{p} \geq \overline{T_{p}}$. The proof with reversed inequalities is analogous.

Proof of Proposition 3 In order to compare $\tilde{T}_{a}$ and $\overline{T_{a}}$, we evaluate (12) (where $\tilde{T}_{a}$ is determined) for $T_{a}=\overline{T_{a}}$. By Jensen's inequality and since $\mathbb{E}\left(\tilde{q_{0}}\right)=q_{0}, U_{c q q} \leq 0$ implies $\mathbb{E}\left[U_{c}\left(y-s^{\star}+f\left(s^{\star}\right)-\overline{T_{a}}, \tilde{q_{0}}-g\left(s^{\star}\right)+m \overline{T_{a}}\right)\right] \leq U_{c}\left(y-s^{\star}+f\left(s^{\star}\right)-\overline{T_{a}}, q_{0}-\right.$ $\left.g\left(s^{\star}\right)+m \overline{T_{a}}\right)$ and $U_{q q q} \geq 0$ implies $\mathbb{E}\left[U_{q}\left(y-s^{\star}+f\left(s^{\star}\right)-\overline{T_{a}}, \tilde{q_{0}}-g\left(s^{\star}\right)+m \overline{T_{a}}\right)\right] \geq$ $U_{q}\left(y-s^{\star}+f\left(s^{\star}\right)-\overline{T_{a}}, q_{0}-g\left(s^{\star}\right)+m \overline{T_{a}}\right)$. The two previous inequalities, together with (11), imply

$$
\begin{aligned}
& -\mathbb{E}\left[U_{c}\left(y-s^{\star}+f\left(s^{\star}\right)-\overline{T_{a}}, \tilde{q_{0}}-g\left(s^{\star}\right)+m \overline{T_{a}}\right)\right] \\
& \quad+m \mathbb{E}\left[U_{q}\left(y-s^{\star}+f\left(s^{\star}\right)-\overline{T_{a}}, \tilde{q_{0}}-g\left(s^{\star}\right)+m \overline{T_{a}}\right)\right] \geq 0 .
\end{aligned}
$$


Since, by second-order condition left-hand sides of (12) is decreasing in $T_{a}$, this implies $\tilde{T}_{a} \geq \overline{T_{a}}$. The proof with reversed inequalities is analogous.

Proof of Proposition 4 In order to compare $\tilde{T}_{a}$ and $\overline{T_{a}}$, we evaluate (13) (where $\tilde{T}_{a}$ is determined) for $T_{a}=\overline{T_{a}}$. By Jensen's inequality and since $\mathbb{E}(\tilde{m})=m, U_{c q q} \leq 0$ implies

$$
\begin{aligned}
& \mathbb{E} {\left[U_{c}\left(y-s^{\star}+f\left(s^{\star}\right)-\overline{T_{a}}, q_{0}-g\left(s^{\star}\right)+\tilde{m} \overline{T_{a}}\right)\right] } \\
& \leq U_{c}\left(y-s^{\star}+f\left(s^{\star}\right)-\overline{T_{a}}, q_{0}-g\left(s^{\star}\right)+m \overline{T_{a}}\right) .
\end{aligned}
$$

Again by Jensen's inequality

$$
\begin{aligned}
& \mathbb{E}\left[\tilde{m} U_{q}\left(y-s^{\star}+f\left(s^{\star}\right)-\overline{T_{a}}, q_{0}-g\left(s^{\star}\right)+\tilde{m} \overline{T_{a}}\right)\right] \\
& \quad \geq m U_{q}\left(y-s^{\star}+f\left(s^{\star}\right)-\overline{T_{a}}, q_{0}-g\left(s^{\star}\right)+m \overline{T_{a}}\right)
\end{aligned}
$$

if the function $\Phi(m)=m U_{q}\left(y-s^{\star}+f\left(s^{\star}\right)-T_{a}, q_{0}-g\left(s^{\star}\right)+m T_{a}\right)$ is convex with respect to $m$. After simple calculus we have $\Phi^{\prime \prime}(m)=2 T_{a} U_{q q}+m T_{a}^{2} U_{q q q} \geq 0$, which is equivalent to $-m T_{a} \frac{U_{q q q}}{U_{q q}} \geq 2$. This means that $U_{c q q} \leq 0$ and $-m T_{a} \frac{U_{q q q}}{U_{q q}} \geq 2$ imply (45) and (46). Inequalities (45) and (46), together with (11), imply

$$
\begin{aligned}
& -\mathbb{E}\left[U_{c}\left(y-s^{\star}+f\left(s^{\star}\right)-\overline{T_{a}}, q_{0}-g\left(s^{\star}\right)+\tilde{m} \overline{T_{a}}\right)\right] \\
& +\mathbb{E}\left[\tilde{m} U_{q}\left(y-s^{\star}+f\left(s^{\star}\right)-\overline{T_{a}}, q_{0}-g\left(s^{\star}\right)+\tilde{m} \overline{T_{a}}\right)\right] \geq 0 .
\end{aligned}
$$

Finally, since by the second-order condition the left-hand side of (13) is decreasing in $T_{a}$, (47) implies $\tilde{T}_{a} \geq \overline{T_{a}}$. The proof with reversed inequalities is analogous.

Proof of Proposition 5 The proof of a) is trivial. Since (18) and (21) are equal $\bar{s}=\tilde{s}$. By (7) this implies $\overline{T_{p}}=\tilde{T}_{p}$. With reference to b), we compare $\tilde{T}_{a}$ and $\overline{T_{a}}$ by evaluating (19) for $T_{a}=\overline{T_{a}}$. By Jensen's inequality, $U_{c q q} \leq 0$ implies $\mathbb{E}\left[U_{c}(y-\bar{s}+f(\bar{s})\right.$ $\left.\left.-\overline{T_{a}}, \tilde{q_{0}}+m \overline{T_{a}}-k \bar{s}\right)\right] \leq U_{c}\left(y-\bar{s}+f(\bar{s})-\overline{T_{a}}, q_{0}+m \overline{T_{a}}-k \bar{s}\right)$ while $U_{q q q} \geq 0$ implies $\mathbb{E}\left[U_{q}\left(y-\bar{s}+f(\bar{s})-\overline{T_{a}}, \tilde{q_{0}}+m \overline{T_{a}}-k \bar{s}\right)\right] \geq U_{q}\left(y-\bar{s}+f(\bar{s})-\overline{T_{a}}, q_{0}+m \overline{T_{a}}-k \bar{s}\right)$. Given that $\tilde{s}=\bar{s}$, these two conditions together imply that the left-hand side of (19), evaluated for $T_{a}=\overline{T_{a}}$, is larger than the left hand side of (14) and thus is larger than zero. Since, by second-order conditions, (19) is decreasing in $T_{a}$, this implies $\tilde{T}_{a} \geq \overline{T_{a}}$. The proof with reversed inequalities is analogous.

Proof of Proposition 6 In order to order to prove a), we consider the left-hand side of (18) evaluated at $s=\tilde{s}$. Multiplying and dividing the fraction $\frac{k}{m}$ by $\mathbb{E}\left[U_{q}(y-\right.$ $\left.\left.\tilde{s}+f(\tilde{s})-\tilde{T}_{a}, q_{0}+\tilde{m} \tilde{T}_{a}-k \tilde{s}\right)\right]$ we get that this is equivalent to $f^{\prime}(\tilde{s})-1-$ $\frac{k \mathbb{E}\left[U_{q}\left(y-\tilde{s}+f(\tilde{s})-\tilde{T}_{a}, q_{0}+\tilde{m} \tilde{T}_{a}-k \tilde{s}\right)\right]}{m \mathbb{E}\left[U_{q}\left(y-\tilde{s}+f(\tilde{s})-\tilde{T}_{a}, q_{0}+\tilde{m} \tilde{T}_{a}-k \tilde{s}\right)\right]}$. We now compare it with the left-hand side of (24). Note that $\mathbb{E}\left[\tilde{m} U_{q}\left(y-\tilde{s}+f(\tilde{s})-\tilde{T}_{a}, q_{0}+\tilde{m} \tilde{T}_{a}-k \tilde{s}\right)\right]=m \mathbb{E}\left[U_{q}(y-\tilde{s}+f(\tilde{s})-\right.$ $\left.\left.\tilde{T}_{a}, q_{0}+\tilde{m} \tilde{T}_{a}-k \tilde{s}\right)\right]+\operatorname{cov}\left[\tilde{m}, U_{q}\left(y-\tilde{s}+f(\tilde{s})-\tilde{T}_{a}, q_{0}+\tilde{m} \tilde{T}_{a}-k \tilde{s}\right)\right]$. Given the concavity of the utility function $\left(U_{q q}<0\right), \operatorname{cov}\left[\tilde{m}, U_{q}\left(y-\tilde{s}+f(\tilde{s})-\tilde{T}_{a}, q_{0}+\tilde{m} \tilde{T}_{a}-k \tilde{s}\right)\right]<0$. This implies $\mathbb{E}\left[\tilde{m} U_{q}\left(y-\tilde{s}+f(\tilde{s})-\tilde{T}_{a}, q_{0}+\tilde{m} \tilde{T}_{a}-k \tilde{s}\right)\right]<m \mathbb{E}\left[U_{q}(y-\tilde{s}+f(\tilde{s})-\right.$ 
$\left.\left.\tilde{T}_{a}, q_{0}+\tilde{m} \tilde{T}_{a}-k \tilde{s}\right)\right]$. This result, together with (24) and the value of the left-hand side of (18) computed at the beginning of the Proof implies in turn

$$
\begin{aligned}
f^{\prime}(\tilde{s})-1-\frac{k}{m}= & f^{\prime}(\tilde{s})-1-\frac{k \mathbb{E}\left[U_{q}\left(y-\tilde{s}+f(\tilde{s})-\tilde{T}_{a}, q_{0}+\tilde{m} \tilde{T}_{a}-k \tilde{s}\right)\right]}{m \mathbb{E}\left[U_{q}\left(y-\tilde{s}+f(\tilde{s})-\tilde{T}_{a}, q_{0}+\tilde{m} \tilde{T}_{a}-k \tilde{s}\right)\right]} \\
> & f^{\prime}(\tilde{s})-1 \\
& -\frac{k \mathbb{E}\left[U_{q}\left(y-\tilde{s}+f(\tilde{s})-\tilde{T}_{a}, q_{0}+\tilde{m} \tilde{T}_{a}-k \tilde{s}\right)\right]}{\mathbb{E}\left[\tilde{m} U_{q}\left(y-\tilde{s}+f(\tilde{s})-\tilde{T}_{a}, q_{0}+\tilde{m} \tilde{T}_{a}-k \tilde{s}\right)\right]}=0
\end{aligned}
$$

Since the left-hand side of (18) is decreasing in $s$, this last result implies $\bar{s}>\tilde{s}$. By (7), this implies in turn $\tilde{T}_{p}>\overline{T_{p}}$.

In order to prove (b) we define the left-hand side of (15) evaluated for generic $s$ and $T_{a}$ as $\Psi\left(s, T_{a}, m, k\right)$. By comparing (15) and (23) by means of Jensen's inequality, we have that $U_{c q q} \geq 0$ and $U_{q q q} \leq 0$ ensure

$$
\mathbb{E}\left[\Psi\left(\bar{s}, \overline{T_{a}}, \tilde{m}, k\right)\right] \geq \Psi\left(\bar{s}, \overline{T_{a}}, m, k\right)=0 .
$$

By a) we know that $\tilde{s}<\bar{s}$. Since $\frac{\partial \Psi}{\partial s}<0, \mathbb{E}\left[\Psi\left(\tilde{s}, \overline{T_{a}}, \tilde{m}, k\right)\right]>\mathbb{E}\left[\Psi\left(\bar{s}, \overline{T_{a}}, \tilde{m}, k\right)\right]$. This together with (49) implies $\mathbb{E}\left[\Psi\left(\tilde{s}, \overline{T_{a}}, \tilde{m}, k\right)\right]>\Psi\left(\bar{s}, \overline{T_{a}}, m, k\right)=0$. Since $\frac{\partial \Psi}{\partial T_{a}}>$ 0 and given (15) and (23), this last result implies $\tilde{T}_{a}<\overline{T_{a}}$.

Proof of Proposition 7 In order to prove (a), we compare the left-hand side of (27) with the left-hand side of (18) evaluated at $s=\tilde{s}$, which is equivalent to $f^{\prime}(\tilde{s})-$ $1-\frac{k \mathbb{E}\left[U_{q}\left(y-\tilde{s}+f(\tilde{s})-\tilde{T}_{a}, q_{0}+\tilde{m} \tilde{T}_{a}-k \tilde{s}\right)\right]}{m \mathbb{E}\left[U_{q}\left(y-\tilde{s}+f(\tilde{s})-\tilde{T}_{a}, q_{0}+\tilde{m} \tilde{T}_{a}-k \tilde{s}\right)\right]}$. Note that $\mathbb{E}\left[\tilde{k} U_{q}\left(y-\tilde{s}+f(\tilde{s})-\tilde{T}_{a}, q_{0}+\right.\right.$ $\left.\left.m \tilde{T}_{a}-\tilde{k} \tilde{s}\right)\right]=k \mathbb{E}\left[U_{q}\left(y-\tilde{s}+f(\tilde{s})-\tilde{T}_{a}, q_{0}+m \tilde{T}_{a}-\tilde{k} \tilde{s}\right)\right]+\operatorname{cov}\left[\tilde{k}, U_{q}(y-\tilde{s}+\right.$ $\left.\left.f(\tilde{s})-\tilde{T}_{a}, q_{0}+m \tilde{T}_{a}-\tilde{k} \tilde{s}\right)\right]$, where $\operatorname{cov}\left[\tilde{k}, U_{q}\left(y-\tilde{s}+f(\tilde{s})-\tilde{T}_{a}, q_{0}+m \tilde{T}_{a}-\tilde{k} \tilde{s}\right)\right]>0$ for the concavity of the utility function $\left(U_{q q}<0\right)$. This implies that $\mathbb{E}\left[\tilde{k} U_{q}(y-\tilde{s}+\right.$ $\left.\left.f(\tilde{s})-\tilde{T}_{a}, q_{0}+m \tilde{T}_{a}-\tilde{k} \tilde{s}\right)\right]>k \mathbb{E} U_{q}\left(y-\tilde{s}+f(\tilde{s})-\tilde{T}_{a}, q_{0}+m \tilde{T}_{a}-\tilde{k} \tilde{s}\right)$ implying, in turn that

$$
\begin{aligned}
f^{\prime}(\tilde{s})-1-\frac{k}{m}= & f^{\prime}(\tilde{s})-1-\frac{k \mathbb{E}\left[U_{q}\left(y-\tilde{s}+f(\tilde{s})-\tilde{T}_{a}, q_{0}+m \tilde{T}_{a}-\tilde{k} \tilde{s}\right)\right]}{m \mathbb{E}\left[U_{q}\left(y-\tilde{s}+f(\tilde{s})-\tilde{T}_{a}, q_{0}+m \tilde{T}_{a}-\tilde{k} \tilde{s}\right)\right]} \\
> & f^{\prime}(\tilde{s})-1 \\
& -\frac{\mathbb{E}\left[\tilde{k} U_{q}\left(y-\tilde{s}+f(\tilde{s})-\tilde{T}_{a}, q_{0}+m \tilde{T}_{a}-\tilde{k} \tilde{s}\right)\right]}{m \mathbb{E}\left[U_{q}\left(y-\tilde{s}+f(\tilde{s})-\tilde{T}_{a}, q_{0}+m \tilde{T}_{a}-\tilde{k} \tilde{s}\right)\right]}=0 .
\end{aligned}
$$

Since the left-hand side of (18) is decreasing in $s$, this last result implies $\bar{s}>\tilde{s}$. By (7), this implies in turn $\tilde{T}_{p}>\overline{T_{p}}$. 
In order to prove (b) we define the left-hand side of (14) for generic $s$ and $T_{a}$ as $\Theta\left(s, T_{a}, m, k\right)$. By comparing (14) and (25) by means of Jensen's inequality, we have that $U_{c q q} \geq 0$ and $U_{q q q} \leq 0$ ensure

$$
\mathbb{E}\left[\Theta\left(\bar{s}, \overline{T_{a}}, m, \tilde{k}\right)\right] \leq \Theta\left(\bar{s}, \overline{T_{a}}, m, k\right)=0
$$

By (a) we know that $\tilde{s}<\bar{s}$. Since $\frac{\partial \Theta}{\partial s}>0, \mathbb{E}\left[\Theta\left(\bar{s}, \overline{T_{a}}, m, \tilde{k}\right)\right]>\mathbb{E}\left[\Theta\left(\tilde{s}, \overline{T_{a}}, m, \tilde{k}\right)\right]$. This together with (50), implies $\mathbb{E}\left[\Theta\left(\tilde{s}, \overline{T_{a}}, m, \tilde{k}\right)\right]<\Theta\left(\bar{s}, \overline{T_{a}}, m, k\right)$. Since $\frac{\partial \Theta}{\partial T_{a}}<0$ and given (14) and (25), this last result implies $\tilde{T}_{a}<\overline{T_{a}}$.

Proof of Proposition 9 We prove the proposition for one direction of the inequalities. The proof for the other direction is similar. We first prove (a). By Lemma 8 (a), $(-1)^{N} U_{(1),(N)} \leq 0$ implies $\mathbb{E}\left[U_{(1),(0)}\left(y-s\left(\tilde{q_{1}}\right)+f\left(s\left(\tilde{q_{1}}\right)\right), \tilde{q_{2}}-g\left(s\left(\tilde{q_{1}}\right)\right)\right)\right] \leq$ $\mathbb{E}\left[U_{(1),(0)}\left(y-s\left(\tilde{q_{1}}\right)+f\left(s\left(\tilde{q_{1}}\right)\right), \tilde{q_{1}}-g\left(s\left(\tilde{q_{1}}\right)\right)\right)\right]$ and $(-1)^{N} U_{(0),(N+1)} \geq 0$ implies $\mathbb{E}\left[U_{(0),(1)}\left(y-s\left(\tilde{q_{1}}\right)+f\left(s\left(\tilde{q_{1}}\right)\right), \tilde{q_{2}}-g\left(s\left(\tilde{q_{1}}\right)\right)\right)\right] \geq \mathbb{E}\left[U_{(0),(1)}\left(y-s\left(\tilde{q_{1}}\right)+f\left(s\left(\tilde{q_{1}}\right)\right)\right.\right.$, $\left.\left.\tilde{q_{1}}-g\left(s\left(\tilde{q_{1}}\right)\right)\right)\right]$. By Eq. (8) we know that when $q_{0}=\tilde{q_{1}}$ and $s=s\left(\tilde{q_{1}}\right)$, the lefthand side of (8) is null. This, together with the two previous inequalities derived by Lemma 8, implies that the left-hand side of (8) evaluated for $q_{0}=\tilde{q_{2}}$ and $s=s\left(\tilde{q_{1}}\right)$ is negative. Since the left-hand side of $(8)$ is decreasing in $s$, this implies $s\left(\tilde{q_{2}}\right) \leq s\left(\tilde{q_{1}}\right)$. By (7) this implies in turn $T_{p}\left(\tilde{q_{2}}\right) \geq T_{p}\left(\tilde{q_{1}}\right)$ in the model with Pigouvian tax (Sect. 3).

We now prove (b). By Lemma $8(\mathrm{a}),(-1)^{N} U_{(1),(N)} \leq 0$ implies $\mathbb{E}\left[U_{(1),(0)}\left(y-s^{\star}+\right.\right.$ $\left.\left.f\left(s^{\star}\right)-T_{a}\left(\tilde{q_{1}}\right), \tilde{q_{2}}-g\left(s^{\star}\right)+m T_{a}\left(\tilde{q_{1}}\right)\right)\right] \leq \mathbb{E}\left[U_{(1),(0)}\left(y-s^{\star}+f\left(s^{\star}\right)-T_{a}\left(\tilde{q_{1}}\right), \tilde{q_{1}}-\right.\right.$ $\left.\left.g\left(s^{\star}\right)+m T_{a}\left(\tilde{q_{1}}\right)\right)\right]$ and $(-1)^{N} U_{(0),(N+1)} \geq 0$ implies $\mathbb{E}\left[U_{(0),(1)}\left(y-s^{\star}+f\left(s^{\star}\right)-\right.\right.$ $\left.\left.T_{a}\left(\tilde{q_{1}}\right), \tilde{q_{2}}-g\left(s^{\star}\right)+m T_{a}\left(\tilde{q_{1}}\right)\right)\right] \geq \mathbb{E}\left[U_{(0),(1)}\left(y-s^{\star}+f\left(s^{\star}\right)-T_{a}\left(\tilde{q_{1}}\right), \tilde{q_{1}}-g\left(s^{\star}\right)+\right.\right.$ $\left.\left.m T_{a}\left(\tilde{q_{1}}\right)\right)\right]$. By equation (12) we know that when $q_{0}=\tilde{q_{1}}$ and $T_{a}=T_{a}\left(\tilde{q_{1}}\right)$, the left-hand side of (12) is null. This, together with the two previous inequalities derived by Lemma 8 , implies that the left-hand side of (12) evaluated for $q_{0}=\tilde{q_{2}}$ and $T_{a}=$ $T_{a}\left(\tilde{q_{1}}\right)$ is positive. Since the left-hand side of (12) is decreasing in $T_{a}$, this implies $T_{a}\left(\tilde{q_{2}}\right)>T_{a}\left(\tilde{q_{1}}\right)$.

Proof of Corollary 10 The corollary is proved by applying Lemma 8 (b) and following the same steps in the proof of Proposition 9.

Proof of Proposition 11 We prove the proposition for one direction of the inequalities. The proof for the other direction is similar. By Lemma $8(\mathrm{a}),(-1)^{N} U_{(1),(N)} \leq 0$ implies

$$
\begin{aligned}
\mathbb{E} & {\left[U_{(1),(0)}\left(y-s^{\star}+f\left(s^{\star}\right)-T_{a}\left(\tilde{m}_{1}\right), q_{0}-g\left(s^{\star}\right)+\tilde{m}_{2} T_{a}\left(\tilde{m}_{1}\right)\right)\right] } \\
& \leq \mathbb{E}\left[U_{(1),(0)}\left(y-s^{\star}+f\left(s^{\star}\right)-T_{a}\left(\tilde{m}_{1}\right), q_{0}-g\left(s^{\star}\right)+\tilde{m}_{1} T_{a}\left(\tilde{m}_{1}\right)\right)\right] .
\end{aligned}
$$

Defining the function $L(m)=m U_{(0),(1)}\left(y-s^{\star}+f\left(s^{\star}\right)-T_{a}, q_{0}-g\left(s^{\star}\right)+m T_{a}\right)$ and applying Lemma 8 (a) to this function, we get

$$
\begin{aligned}
& \mathbb{E}\left[\tilde{m}_{2} U_{(0),(1)}\left(y-s^{\star}+f\left(s^{\star}\right)-T_{a}\left(\tilde{m}_{1}\right), q_{0}-g\left(s^{\star}\right)+\tilde{m}_{2} T_{a}\left(\tilde{m}_{1}\right)\right)\right] \\
& \geq \mathbb{E}\left[\tilde{m}_{1} U_{(0),(1)}\left(y-s^{\star}+f\left(s^{\star}\right)-T_{a}\left(\tilde{m}_{1}\right), q_{0}-g\left(s^{\star}\right)+\tilde{m}_{1} T_{a}\left(\tilde{m}_{1}\right)\right)\right]
\end{aligned}
$$


if $(-1)^{N} L(m)_{(0),(N)} \geq 0$. By differentiating $L(m)$, it is easy to see that this inequality is equivalent to $-m T_{a} \frac{U_{(0),(N+1)}}{U_{(0),(N)}} \geq N$. By Eq. (13) we know that when $m=\tilde{m}_{1}$ and $T_{a}=T_{a}\left(\tilde{m}_{1}\right)$, the left-hand side of (13) is null. This, together with (51) and (52), implies that the left-hand side of (13) evaluated for $m=\tilde{m}_{2}$ and $T_{a}=T_{a}\left(\tilde{m}_{1}\right)$ is positive. Since the left-hand side of (13) is decreasing in $T_{a}$, this implies $T_{a}\left(\tilde{m}_{2}\right)>$ $T_{a}\left(\tilde{m}_{1}\right)$ in the model with the abatement policy (Sect. 4).

Proof of Corollary 12 The corollary is proved by applying Lemma 8 (b) and following the same steps as in the proof of Proposition 11.

Proof of Proposition 13 We prove the proposition for one direction of the inequalities. The proof for the other direction is similar. By Lemma $8(\mathrm{a}),(-1)^{N} U_{(1),(N)} \leq 0$ implies

$$
\begin{aligned}
\mathbb{E} & {\left[U_{(1),(0)}\left(y-s\left(\tilde{k_{1}}\right)+f\left(s\left(\tilde{k_{1}}\right)\right), q_{0}-\tilde{k_{2}} s\left(\tilde{k_{1}}\right)\right)\right] } \\
& \leq \mathbb{E}\left[U_{(1),(0)}\left(y-s\left(\tilde{k_{1}}\right)+f\left(s\left(\tilde{k_{1}}\right)\right), q_{0}-\tilde{k_{1}} s\left(\tilde{k_{1}}\right)\right)\right] .
\end{aligned}
$$

Defining the function $Z(k)=k U_{(0),(1)}\left(y-s+f(s), q_{0}-k s\right)$ and applying Lemma 8 (a) to this function, we get

$$
\begin{aligned}
& \mathbb{E}\left[\tilde{k_{2}} U_{(0),(1)}\left(y-s\left(\tilde{k_{1}}\right)+f\left(s\left(\tilde{k_{1}}\right)\right), q_{0}-\tilde{k_{2}} s\left(\tilde{k_{1}}\right)\right)\right] \\
& \quad \geq \mathbb{E}\left[\tilde{k_{1}} U_{(0),(1)}\left(y-s\left(\tilde{k_{1}}\right)+f\left(s\left(\tilde{k_{1}}\right)\right), q_{0}-\tilde{k_{1}} s\left(\tilde{k_{1}}\right)\right)\right]
\end{aligned}
$$

is satisfied if $-(1)^{N} Z(k)_{(0),(N)} \geq 0$. By differentiating $Z(k)$, it is easy to see that this inequality is equivalent to $(-1)^{N} k s \frac{U_{(0),(N+1)}}{U_{(0),(N)}} \leq(-1)^{N} N$. By Eq. (10) we know that when $k=\tilde{k_{1}}$ and $s=s\left(\tilde{k_{1}}\right)$, the left-hand side of (10) is null. This, together with (53) and (54), implies that the left-hand side of (10) evaluated for $k=\tilde{k_{2}}$ and $s=s\left(\tilde{k_{1}}\right)$ is negative. Since the left-hand side of (10) is decreasing in $s$, this implies $s\left(\tilde{k_{2}}\right) \leq s\left(\tilde{k_{1}}\right)$. By (7) this implies in turn $T_{p}\left(\tilde{k_{2}}\right) \geq T_{p}\left(\tilde{k_{1}}\right)$ in the Pigouvian tax model (Sect. 3).

Proof of Corollary 14 The corollary is proved by applying Lemma 8 (b) and following the same steps as in the proof of Proposition 13.

\section{References}

Angelopoulos K, Economides G, Philippopoulos A (2010) What is the best environmental policy? Taxes, permits and rules under economic and environmental uncertainty. CESifo Working Paper No. 2980 Ayong Le Kama A (2001) Preservation and exogenous uncertain future preferences. Econ Theory 18:745752

Ayong Le Kama A, Schubert K (2004) Growth, environment and uncertain future preferences. Environ Resour Econ 28:31-53

Baumol WA, Oates WE (1988) The theory of environmental policy. Cambridge University Press, Cambridge 
Beltratti A, Chichilnisky G, Heal GM (1998) Uncertain future preferences and conservation. In: Chichilnisky G, Heal M, Vercelli A (eds) Sustainability: dynamics and uncertainty, pp 257-275. Kluwer Academic Pubblishers, Dordrecht

Chiu WH, Eeckhoudt L (2010) The effects of stochastic wages and non-labor income on labor supply: update and extensions. J Econ (forthcoming)

Courbage C (2001) On bivariate risk premia. Theory Decis 50:29-34

Courbage C, Rey B (2007) Precautionary saving in the presence of other risks. Econ Theory 32:417-424

Denuit MM, Eeckhoudt L, Menegatti M (2011) Correlated risks, bivariate utility and optimal choices. Econ Theory 46:39-54

Drèze J, Modigliani F (1972) Consumption decision under uncertainty. J Econ Theory 5:308-335

Economides G, Philippopoulos A (2008) Growth enhancing policy is the means to sustain the environment. Rev Econ Dyn 11:207-219

Eeckhoudt L, Gollier C (2005) The impact of prudence on optimal prevention. Econ Theory 26:989-994

Eeckhoudt L, Rey B, Schlesinger H (2007) A good sign for multivariate risk taking. Manag Sci 53:117-124

Eeckhoudt L, Schlesinger H (2006) Putting risk in its proper place. Am Econ Rev 96:280-289

Eeckhoudt L, Schlesinger H (2008) Changes in risk and the demand for savings. J Monet Econ 55:1329_ 1336

Ekern S (1980) Increasing Nth degree risk. Econ Lett 6:329-333

Finkelshtain I, Kella O, Scarsini M (1999) On risk aversion with two risks. J Math Econ 31:239-250

Geweke J (2001) A note on some limitations of CRRA utility. Econ Lett 71:341-345

Gollier C, Jullien B, Treich N (2000) Scientific progress and irreversibility: an economic interpretation of the precautionary principle. J Public Econ 75:229-253

Gradus R, Smulders S (1993) The trade-off between environmental care and long-term growth-pollution in three prototype growth model. J Econ 1:25-51

Gupta MR, Barman TR (2009) Fiscal policies, environmental pollution and economic growth. Econ Model 26:1018-1028

Heal GM (1984) Interaction between economy and climate: a framework for policy design uncertainty. In: Smith VK, White AD (eds) Advances in applied microeconomics, vol 2. JAI Press, Stamford

Heal G, Kriström B (2002) Uncertainty and climate change. Environ Resour Econ 22:3-39

Helfand GE, Berck P, Maull T (2003) The theory of pollution policy. Handbook of Environmental Economics, Chap 6, vol 1, pp 249-303

Ingersoll JE (1987) Theory of financial decision making. Rowman and Littlefield, Totowa

IPCC (2007) Fourth Assessment Report: Climate Change 2007: Synthesis Report, IPCC

Keeler K, Bolker BM, Bradford DF (2004) Uncertain climate thresholds and optimal economic growth. J Environ Econ Manag 48:723-741

Kimball MS (1990) Precautionary savings in the small and in the large. Econometrica 58:53-73

Leland H (1968) Saving and uncertainty: the precautionary demand for saving. Q J Econ 82:465-473

Menegatti M (2001) On the conditions for precautionary saving. J Econ Theory 98:189-193

Menegatti M (2007) A new interpretation for the precautionary saving motive: a note. J Econ 92:275-280

Menegatti M (2009a) Precautionary saving in the presence of other risks: a comment. Econ Theory 39:473-476

Menegatti M (2009b) Optimal saving in the presence of two risks. J Econ 96:277-288

Menegatti M (2009c) Optimal prevention and prudence in a two-period model. Math Soc Sci 58:393-397

Menezes C, Geiss C, Tressler J (1980) Increasing downside risk. Am Econ Rev 70:921-932

Menezes C, Wang H (2005) Increasing outer risk. J Math Econ 41:875-886

Michel P, Rotillon G(1995) Disutility on pollution and endogenous growth. Environ Resour Econ 6:279-300

Mohtadi H (1996) Environment growth, and optimal policy design. J Public Econ 63:119-140

Nordhaus WD (1994) Managing the global commons: the economics of climate change. MIT Press, Cambridge

Nordhaus WD (2009) An analysis of the dismal theorem (unpublished)

Nordhaus WD, Boyer J (2000) Warming the world: economic models of global warming. MIT Press, Cambridge

Pratt JW (1964) Risk aversion in the small and in the large. Econometrica 32:122-136

Pratt JW (1988) Aversion to one risk in the presence of others. J Risk Uncertain 1:395-413

Pigou AC (1924) The economics of welfare. 2nd edn. McMillan, London

Pindyck RS (2000) Irreversibilities and the timing of environmental policy. Resour Energy Econ 22:233260 
Pindyck RS (2002) Optimal timing problems in environmental economics. J Econ Dyn 22:1677-1697

Pindyck RS (2009) Uncertain outcomes and climate change policy. NBER Working Paper 15259

Rothschild M, Stiglitz J (1971) Increasing risk II: economic consequences. J Econ Theory 3:66-84

Sandmo A (1970) The effect of uncertainty on saving decisions. Rev Econ Stud 37:353-360

Smulders S, Gradus R (1996) Pollution abatement and long-term growth. Eur J Political Econ 12:505-532

Soretz S (2007) Efficient dynamic pollution taxation in an uncertain environment. Environ Resour Econ $36: 57-84$

Stone BL (1970) Risk, return and equilibrium. MIT Press, Cambridge

Ulph A, Ulph D (1997) Global warming, irreversibility and learning. Econ J 107:636-650

United Nations (1997) Glossary of environment statistics, studies in methods, Series F, No. 67. United Nations, New York

Weitzman ML (2009a) On modeling and interpreting the economics of catastrophic climate change. Rev Econ Stat 91:1-19

Weitzman ML (2009b) Reactions to the Nordhaus critique (unpublished)

Weitzman ML (2009c) Additive damages, fat-tailed climate dynamics, and uncertain discounting. Economics, The Open-Access, Open-Assessment E-journal (discussion paper)

Xepapadeas A (2005) Economic growth and the environment. Handbook of environmental economics, Chap 23, vol 3, pp 1219-1271 